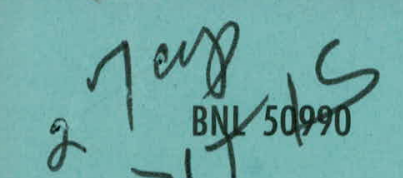

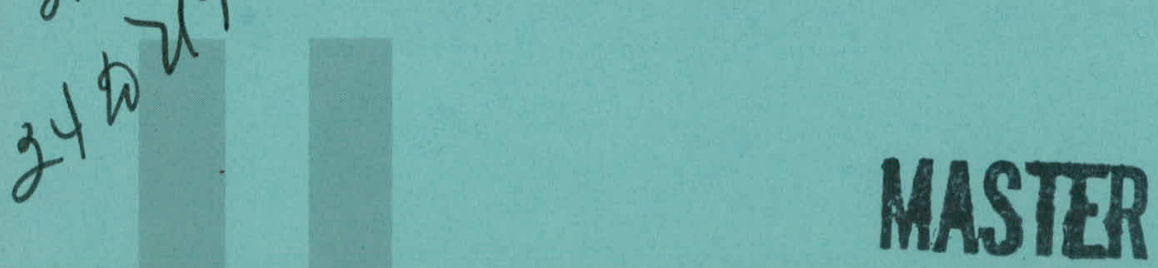 \\ A FEASIBILITY STUDY ON THE USE OF A ROTATING FLUIDIZED BED AS A DUST FILTER
}

Robert Pfeffer and Frank B. Hill

September 1978

Prepared for the DIVISION OF CHEMICAL SCIENCES

U.S. DEPARTMENT OF ENERGY

WASHINGTON, D.C.

CHEMICAL SCIENCES DIVISION

DEPARTMENT OF ENERGY AND ENVIRONMENT

BROOKHAVEN NATIONAL LABORATORY ASSOCIATED UNIVERSITIES, INC.

UNDER CONTRACT NO. EY-76-C-02-0016 WITH THE

UNITED STATES DEPARTMENT OF ENERGY 


\section{DISCLAIMER}

This report was prepared as an account of work sponsored by an agency of the United States Government. Neither the United States Government nor any agency Thereof, nor any of their employees, makes any warranty, express or implied, or assumes any legal liability or responsibility for the accuracy, completeness, or usefulness of any information, apparatus, product, or process disclosed, or represents that its use would not infringe privately owned rights. Reference herein to any specific commercial product, process, or service by trade name, trademark, manufacturer, or otherwise does not necessarily constitute or imply its endorsement, recommendation, or favoring by the United States Government or any agency thereof. The views and opinions of authors expressed herein do not necessarily state or reflect those of the United States Government or any agency thereof. 


\section{DISCLAIMER}

Portions of this document may be illegible in electronic image products. Images are produced from the best available original document. 


\title{
A FEASIBILITY STUDY ON THE USE OF A ROTATING FLUIDIZED BED AS A DUST FILTER
}

\author{
Robert Pfeffer* and Frank B. Hill
}

\section{September 1978}

"Visiting Chemical Engineer. Permanent address:

Dept. of Chemical Engineering, The City University of New York, NY 10031

\author{
Prepared for the \\ DIVISION OF CHEMICAL SCIENCES \\ U.S. DEPARTMENT OF ENERGY \\ WASHINGTON, D.C.
}

CHEMICAL SCIENCES DIVISION DEPARTMENT OF ENERGY AND ENVIRONMENT

BROOKHAVEN NATIONAL LABORATORY UPTON, NEW YORK 11973 
NOTICE

This report was prepared as an account of work sponsored by the United States Government. Neither the United States nor the United States Department of Energy (DOE), nor any of their employees, nor any of their contractors, subcontractors, or thrir r.mplnyrrs, makrs any warranty, express or implied, or assunnes any leyal lixlielity or responsibility for the accuracy, completeness or usefulness of any information, apparatus, product or process disclosed, or represents that its use would not infringe privately owned rights.

Printed in the United States of America Avallable trom

National Technical Information Service

U.S. Department of Commerce

5285 Port Royal Road

Springfield, VA 22161

Price: Printed Copy $\$ 4.50$; Microfiche $\$ 3.00$

May 1979

160 copies 


\section{ABSTRACT}

A brief survey was made of the characteristics of the rotating fluidized bed used as a filter for fine dusts and mists. A sample calculation of overall filtration efficiency was made for a rotating bed operating at minimum fluidization with a velocity of $4 \mathrm{~m} / \mathrm{sec}$ and a g-loading of about 50. Account was taken of removal by the classical mechanisms of diffusion, interception, and inertial impaction. High efficiencies were found for dust particles as small as $1 \mu \mathrm{m}$. The rotating fluid bed filter should have approximately the same collection efficiency and pressure drop as the fixed and moving bed filters operating at the same velocity, but in addition should more readily permit continuous operation without clogging and with effective regeneration.

The same sample calculation of filtration efficiency applied to the conventional $1-\mathrm{g}$ fluid bed operating at 1.5 times the minimum fluidization velocity of $0.2 \mathrm{~m} / \mathrm{sec}$ indicated lower collection efficiencies near $1 \mu \mathrm{m}$ than for the rotating system. The low velocity--and corresponding low throughput--in the stationary system is required to avoid bubble formation which would tend to lower filtration efficiency because of bypassing.

The possible harmful effect on filtration efficiency of reentrainment of dust particles at the high operating velocities of the rotating system as well as the helpful effect of triboelectrification will have to be determined by experiment.

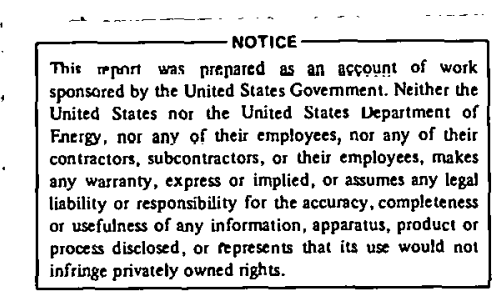




\section{INTRODUCTION}

In recent years a number of studies have been reported on the use of a fixed, fluidized, or spouted bed to filter fine particles from a gas stream. Many of these have been summarized by Clift and Thambimuthu. ${ }^{8}$ With fixed beds, the main operating problem is removal of the collected particles from the filter bed; if the bed becomes saturated, the filtration efficiency quickly drops to zero. The regeneration problem has been overcome by using a moving bed, as in the GBF filter under development by Combustion Power Company, ${ }^{13}$ or by some means of intermittent backflushing, as in the Ducan filter described by Kalen and Zenz. ${ }^{18}$ Both these techniques present substantial operating problems regarding the prevention of clogging, both of the filter bed inlet surface and the bed itself. The idea of using a fluidized bed to act as a dust filter dates back to 1949, when Meissner and Mickley ${ }^{30}$ established that fluidized beds could serve to remove mists and dusts from air at high efficiencies. The basic concept involves using the gas to be filtered as the fluidizing medium to fluidize a bed of collector particles; the collector particles can then be removed and replaced continuously with no operating difficulties. Care must be taken to prevent plugging of the distributor plate of a fluidized bed filter with dust particles, but otherwise operation of the filter is no different from that of a conventional fluidized bed.

Although it has been found that high collection efficiencies for dust particles around $1 \mu \mathrm{m}$ and larger could be attained in shallow beds of spherical. particles with a diameter range of 100 to $600 \mu \mathrm{m}$ in a fluidized bed filter, ${ }^{19,28,46}$ fluidized hed dust collectors have failed to gain 1ndustiial acceptance. In spite of the great advantage that the bed can be regenerated continuously, the use of a fluidized bed for commercial applications is severely limited by the minimum fluidization velocity of the bed particles or granules. Operation at flow rates much higher than this minimum leads to bypassing of gas in the form of large bubbles and consequently to poor collection efficiencies. 3,40 Moreover, bubbling fluidization cannot be used with fragile particles such as sand ${ }^{45}$ because it results in extensive granule attrition. To overcome the limitation of operating the fluidized bed filter 
at velocities near the minimum fluidization velocity and thus achieve higher gas throughputs, Meisen and Mathur ${ }^{29}$ suggested using a spouted bed with particles too coarse (millimeter size) for good fluidization, and Boubel and Junge $^{4}$ did some experiments with a rotating fluidized bed operating at radial acceleration forces $>>1-g$.

It is the purpose of this study to examine the feasibility of using a rotating fluidized bed as a dust collector or filter.

\section{THE ROTATING FLUIDIZED BED}

The rotating fluidized bed ${ }^{25,27}$ ie a device, usually cylindrical in shape, that rotates around its vertical axis of symmetry. The rotating cylindrical surface is porous and serves as the distributor for the bed. The large centripetal forces produced by rotation force the bed material into an annular region at the circumference of the bed. Gas flows radially inward through the porous distributor; when the gas flow is such that the total drag force of the gas against the particles just balances the centripetal force due to the rotation, the bed becomes fluidized. For a given rotational speed, fluidization starts" at the inner surface of the bed, where the radial acceleration is smallest, and eventually reaches the distributor as the gas velocity in increased. Further increases in gas velocity will cause the bed to expand and gas bubbles to appear, as in a conventional fluidized bed. Since the speed of rotation of the bed and hence the radial acceleration can be increased to any desired level (usually between 10 and 50 times the acceleration of gravity), the rotating fluidized bed permits much larger flow rates per unit area of the distributor than are possible in conventinnal. fluidized beds, which operate only against the force of gravity. These much higher gas velocities make the rotating fluidized bed attractive for use as a combustor 10,31 as well as for use as a possible filter for removing dust particles.

The pressure drop and minimum fluidization velocity in a rotating fluidized bed can be obtained by using classical relationships found in the literature for ordinary fluidized beds by replacing the acceleration of gravity, $g$, in these relationships by the radial acceleration, $a_{r}$, produced 
by the rotation of the distributor such that

$$
a_{r}=v_{t}^{2} / r=w_{0}^{2} r
$$

As shown in Figure 1, $L=r_{0}=r_{i}$ is the thickness of the bed, $\varepsilon$ is the void

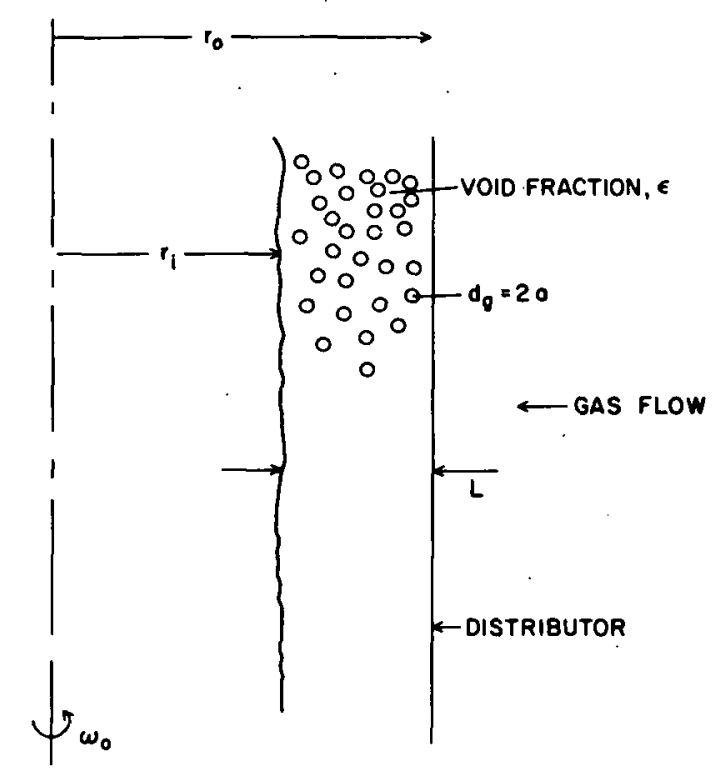

Figure 1. Geometry of a rotating fluidized bed.

fraction, $d_{g}$ is the diameter of bed particle or grain, and $\omega_{0}$ is the rotational speed of the distributor. The free surface of the bed will assume the shape of a paraboloid of revolution, ${ }^{26}$ but a bed rotating at a high enough rotational speed can be considered to be a cylindrical annulus.

The local pressure drop across the bed is given by

$$
\mathrm{dP} / \mathrm{dr}=(1-\varepsilon)\left(\rho_{\mathrm{g}}-\rho_{\mathrm{f}}\right) \mathrm{a}_{\mathrm{r}}
$$

where $\rho_{g}$ is the density of the grains or fluidized particles and $\rho_{f}$ is the density of the fluidizing air. Eq. (2) can be integrated in two different ways. $^{24}$

(a) Assume the tangential velocity to be constant throughout the bed (i.e., $v_{t}=\omega_{0} r_{0}$, its maximum value) so that in Eq. (I) $a_{r}=\omega_{0}{ }_{0}^{2} r_{0}{ }^{2} / r$ and Eq. (2) becomes $\mathrm{dP} / \mathrm{dr}=(1-\varepsilon)\left(\rho_{\mathrm{g}}-\rho_{\mathrm{f}}\right) \omega_{\mathrm{o}}{ }^{2} \mathrm{r}_{\mathrm{o}}^{2} / \mathrm{r}$. Integration gives 


$$
\Delta P=(1-\varepsilon)\left(\rho_{g}-\rho_{f}\right) \omega_{o}^{2} r_{o}^{2} \ln \left(r_{o} / r_{i}\right)
$$

(b) Assume the tangential velocity to vary throughout the bed as $\mathrm{v}_{\mathrm{t}}=\omega_{\mathrm{o}} \mathrm{r}$ (solid-body rotation) so that $\mathrm{Eq}$. (2) becomes $\mathrm{dP} / \mathrm{dr}=$ $(1-\varepsilon)\left(\rho_{g}-\rho_{f}\right) \omega_{o}^{2} r$. Integration gives

$$
\Delta P=(1-\varepsilon)\left(\rho_{g}-\rho_{f}\right) \omega_{o}^{2}\left(r_{o}^{2}-r_{i}^{2}\right) / 2 \text {. }
$$

For thin beds $\left(\mathrm{L} / \mathrm{r}_{0}<<1\right)$ these two expressions yield nearly the same result, but for thick beds Eq. (3) predicts significantly higher pressure drops than dnes Eq. (4). Since the behavior of the tangential velocity in the bed ls not known, the use of either Eq. (3) or Eq. (4) to predict the pressure drop in thick beds must be checked by experiment.

Demircan et a1. ${ }^{10}$ and Metcalfe and Howard ${ }^{31}$ define the pressure drop across the bed as simply the weight of the bed per unit area of the distributor:

$$
\Delta P=\frac{\text { weight of bed }}{\text { area of distributor }}=\frac{(1-\varepsilon)\left(\rho_{g}-\rho_{f}\right) \pi\left(r_{0}{ }^{2}-r_{i}{ }^{2}\right) \text { ha } r}{2 \pi r_{o} h}
$$

where $h$ is the height of the bed. Letting $a_{r}=\omega_{0}^{2} r_{0}$

$$
\Delta P=\frac{(1-\varepsilon)\left(\rho_{g}-\rho_{f}\right) \omega_{o}^{2}\left(r_{o}^{2}-r_{i}^{2}\right)}{2}
$$

which is exactly the result given by Eq. (4). Demircan et al., using bed depths of 3 to $5 \mathrm{~cm}$ in a $20-\mathrm{cm}$-diameter bed, report pressure drops in good agreement with Eq. (4); whereas Metcalfe and Howard found experimental pressure drops in their bed, which was $20 \mathrm{~cm}$ in diameter and about $1.5 \mathrm{~cm}$ thick, to be only $80 \%$ of that predicted by Eq. (4).

To compute the minimum fluidization velocity, $U_{\mathrm{mf}}$, in the rutaling led, one equates the pressure drop, Eq. (2), with the pressure drop given ${ }^{20}$ by the Ergun correlation:

$$
\mathrm{Ga}=150 \frac{1-\varepsilon_{\mathrm{mf}}}{\phi_{\mathrm{S}}{ }^{2} \varepsilon^{3}{ }_{\mathrm{mf}}} \operatorname{Re}_{\mathrm{mf}}+\frac{1.75 \mathrm{Re}^{2} \mathrm{mf}}{\phi_{\mathrm{S}}{ }^{2} \varepsilon^{3}{ }_{\mathrm{mf}}}
$$


where the subscript mf refers to minimum fluidization conditions, and $\mathrm{Ga}$ is the Galileo number defined as

$$
G a=\frac{d_{g}^{3}}{v^{2}}\left(\frac{\rho_{g}}{\rho_{f}}-1\right) g
$$

or, in the case of a rotating fluidized bed, with $g$ replaced by a ${ }_{r}$,

$$
G a=\frac{d_{g}^{3}}{v^{2}}\left(\frac{\rho_{g}}{\rho_{f}}-1\right) a_{r}=\frac{d_{g}^{3}}{v^{2}}\left(\frac{\rho_{g}}{\rho_{f}}-1\right) \omega_{o}{ }^{2} r
$$

and

$$
\operatorname{Re}_{\mathrm{mf}}=\left.\mathrm{U}_{\mathrm{mf}}\right|_{\mathrm{r}} \mathrm{d}_{\mathrm{g}} / \nu
$$

The minimum fluidization velocity defined in Eq. (7) will depend somewhat on position $r$ in the bed, being highest at $r=r_{0}$ (distributor) and lowest at the free surface $r=r_{i}$.

If $i t$ is assumed ${ }^{20}$ that

$$
\frac{1}{\phi_{\mathrm{s}} \varepsilon_{\mathrm{mf}}^{3}} \approx 14 \text { and } \frac{1-\varepsilon_{\mathrm{mf}}}{\phi_{\mathrm{s}}{ }^{2} \varepsilon_{\mathrm{mf}}{ }^{3}} \approx 11
$$

and Eq. (5) is solved for $\operatorname{Re}_{\mathrm{mf}}$, then

$$
\operatorname{Re}_{\mathrm{mf}}=\left[(33.7)^{2}+0.0408 \mathrm{Ga}\right]^{\frac{1}{2}}-33.7
$$

For small particles when the particles or grain Reynolds number, ${ }^{2}{ }_{g}$, is smail, Eq. (5) reduces to

$$
U_{m f \mid r}=d_{g}^{2}\left(\frac{\rho_{g}}{\rho_{f}}-1\right) \frac{\omega_{o}^{2} r}{1650 v}, \quad R e_{g}<20 .
$$

and for large particles

$$
U_{m f \mid r}=\sqrt{\frac{d g}{24.5}\left(\frac{\rho_{g}}{\rho_{f}}-1\right) \omega_{o}{ }^{2} r}, \quad R e_{g}>1000,
$$


where the particle Reynolds number is defined as

$$
\operatorname{Re}_{g}=d_{g} U_{m f} / \nu \text {. }
$$

In the freeboard region, defined as the region radially inward from the free surface of the bed, the gas leaving the surface of the bed is moving both radially and tangentially because of the rotation of the distributor. Close to the bed surface the gas maintains a constant angular momentum so that the tangential velocity varies inversely with radius, and this zone is in irrotational motion much like that in a free vortex, Towards the center of the bed, the flow regime changes ton rntatinnal (forced vortex) so that the combined resulting flow is that of a Rankine vortex.

The pressure drop in the freeboard region is given by

$$
\mathrm{dP} / \mathrm{dr}=\rho_{\mathrm{f}} \mathrm{V}_{\mathrm{t}}^{2} / \mathrm{r}
$$

To evaluate the pressure drop, appropriate expressions for the tangential velocity of the gas, $V_{t}$, must be obtained for both the free and forced vortex regions of the flow before Eq. (II) can be integrated. Such expressions have been proposed both by Levy et $a 1 .^{24}$ and by Chevray et al. ${ }^{7}$ using semiempirical methods. However, the freeboard pressure drop is generally small compared with the bed pressure drop.

Chevray et al. have also computed particle trajectory analyses in the freeboard and found that large particles return quickly to the bed, intermediate sized particles are captured by the vortex and remain in a circular orbit, and very small particles are elutriated. For particles of sizes such that they are captured in the irrotational flow region, a balance between the drag force and the centripetal force caused by the rotation gave the following equation for the minimum particle size captured:

$$
r_{p}=\frac{3}{2} \frac{r}{r_{i}^{2} \omega_{o}} \sqrt{\frac{\rho_{f}}{\rho_{g}} \frac{Q \nu}{\pi h}}
$$

where $Q$ is the volumetric flow of gas, $h$ is the height of the bed, and $r$ is the position in the freeboard where capture occurs. 
Demircan et al. ${ }^{10}$ found that in a bubbling rotating fluidized bed (air flow rates above minimum fluidization) the behavior of the particles after the bubbles burst was quite different from that in a conventional fluidized bed. In the latter, particles tend to splash high above the bed, but in the former, the bed particles, because of their high tangential velocity, proceed in a straight line which transfers them back to the surface of the bed. At lower rotational speeds, the vertical gravitational field causes return of the particles at a lower point on the surface of the bed, augmenting the longitudinal mixing within the bed.

\section{GRANULAR BED FILTRATION THEORY}

In a theoretical analysis of a granular bed filter such as a conventional or a rotating fluidized bed, the bed is usually assumed to be a homogeneous bed of spherical particles of uniform size through which the dusty gas flows. Filtration of the particulate matter is accomplished by the sticking of the dust particles in the gas to the surfaces of the filter elements (granules). It is also assumed that every filter element experiences similar filtration phenomena, and therefore a single-particle efficiency $E$ can be defined so that the filtration efficiency of the entire bed of granules can be computed by summing the effects of all the elcments in the filter. Thus, the theoretical computation of the overall filter efficiency $\eta$ usually first requires predicting the single-particle efficiency E.

Other inherent assumptions are that the dust particle concentration in the gas stream is/low enough not to influence the gas flow field around the filter elements, and that the filtration process is time independent so that each filter element, as well as the entire filter bed, always has the same efficiency. These two assumptions are reasonable for a fluidized bed used to filter relatively dilute dusty gases and subject to continuous recycling and cleaning of the bed granules. The assumption that a particle which approaches a granule to within a distance comparable to its radius will collide with it and stick to it excludes the effect of the surface properties of the two substance coming into contact. For example, the adhesivity of dust particles to each other may be greater than their adhesivity to granules, 
so that dust agglomerates or "trees" may be formed. Furthermore, filtration in a fluidized bed is complicated by dust particle buoyancy and especially by reentrainment: dust particles colliding with a collector or granule or even captured on previous granules can be carried downstream by the gas flow, and this reduces the overall filtration efficiency. These phenomena occur mainly when operating velocity is high and when the collection medium (granules) is almost saturated with dust particles.

The single-particle efficiency $E$ is defined as the total number of dust particles captured by a single granule divided by the total number of particles flowing towards it. in a cylinder of diameter $2 \mathrm{a}$, oriented along the flow direction, as shown in Figure 2. Thus,

$$
E=J / n_{0} U_{0} \pi a^{2}
$$

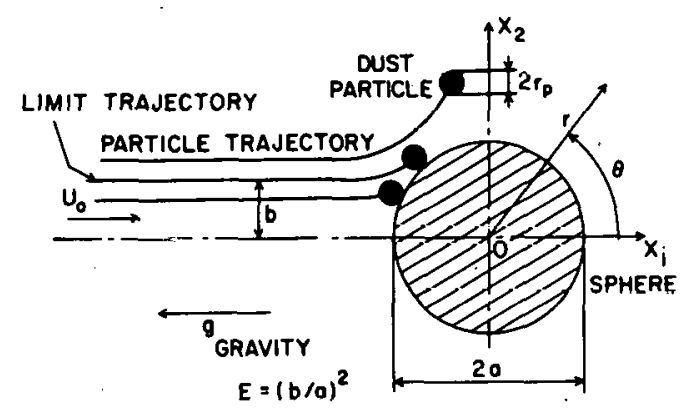

Tigure 2. Inertial deposicion uf particles.

where $J$ is the total dust particle flow rate tuwards the granule surface, $n_{0}$ is the dust concentration, and $U_{0}$ is the gas superflclal velocity. If it ic assumed that the captured parielcles all fluw loward the collector in a coaxial cylinder of diameter $2 b$,

$$
\mathrm{J}=\mathrm{n}_{0} \mathrm{U}_{0} \pi \mathrm{b}^{2}
$$

then the single-particle efficiency $E$ can also be defined as 


$$
E=b^{2} / a^{2}
$$

The computation of $E$ requires knowledge of either the total flow rate $J$ in Eq. (13) or the distance $b$, the so-called distance of the limit or grazing trajectory, in Eq. (13a). Deposition by diffusion is usually obtained from the former and deposition by inertial impaction from the latter.

\section{A. Dust Deposition Mechanisms}

The simplified assumptions discussed above allow the fluidized bed filter to be modeled mathematically. The single-particle collection mechanisms considered to be important are Brownian diffusion, inertial impaction, direct interception, and gravitational sedimentation. Besides these classical deposition mechanisms, deposition by electrostatic phenomena (usually neglected in published theoretical studies of filtration) should have a large influence because of the natural electrostatic charging of the granules as they move about in the fluidized bed, bit the problem of determining the single-particle efficiency due to electrical forces in a bed of particles has not yet been solved.

1. Brownian Diffusion. For particles in the submicron size range, the Brownian motion relative to that of the gas stream is sufficiently intense to produce collisions with a large surface (granule) located in the flow. If this surface retains the particles either by adhesion or by some other effect, a concentration gradient is established and particles diffuse in the direction of the collector. Diffusional deposition increases rapidly with decreasing particle size and decreasing velocity of flow and, neglecting electrostatic effects, is the main mechanism for deposition in the submicron particle size range.

Levich ${ }^{23}$ obtained a solution for the particle flux due to diffusion around a single sphere in the creeping motion ( $\mathrm{Re}_{\mathrm{g}} \rightarrow 0$ ) range in terms of the dimensionless Sherwood number and Peclet number,

$$
\mathrm{Sh}=0.99 \mathrm{Pe}^{1 / 3},
$$


which holds for high Peclet numbers. Substitution of Eq. (15) into Eq. (13) gives

$$
E_{D}=4 \times 0.99 e^{-2 / 3}
$$

where the Peclet number is defined as

$$
\mathrm{Pe}=\mathrm{d}_{\mathrm{g}} \mathrm{U}_{0} / D
$$

and the diffusion coefficient $D$ as

$$
D=\operatorname{rikT} / 6 \pi r_{p} \mu
$$

where $C$ is the Cunningham correction factor, $k$ is the Boltzman constant, $T$ is the absolute temperature, $r_{p}$ is the radius of the dust particle and, $\mu$ is the viscosity of the gas. The Cunningham correction factor is necessary in considering submicron sized particles when the particle size approaches the magnitude of the mean free path of the gas molecules. It can be calculated from

$$
C=1+\frac{2 \ell}{d_{p}}\left(A_{1}+A_{2} \exp \frac{-A_{3} d_{p}}{\ell}\right)
$$

where $A_{1}=1.257, A_{2}=0.40, A_{3}=0.55$, and $\ell$ is the mean free path of gas molecules $\approx 0.065 \mu \mathrm{m}$ at $25^{\circ} \mathrm{C}$ and $1 \mathrm{~atm}$.

For a sphere located in a bed of neighboring particles as in a packed or fluidized bed a correction factor $g(\varepsilon)$ must be introduced in Eq. (16) in place of the constant 0.99 to take into account the effect of the porosity of the bed, $\varepsilon_{\text {. }}$. This was first suggested by Pfeffer, ${ }^{36}$ who used the Happe1 15 sphere in a cell or "free surface" model to represent the gas flow field in a multiparticle system. In Happel's model a bed of particles is represented by a single particle occupying the center of an 1dealized cell. The cell consists of two concentric spheres, an inner sphere representing the solid particle and an outer sphere representing a fluid envelope having an outer "free surface," i.e., a surface under no tangential strcs3. The cell dimensions are such that the ratio of the volume of the gas in the cell to 
the total. volume of the cell is equal to the porosity of the bed. Combining this model with the Levich procedure for solving the diffusion equation, Pfeffer ${ }^{36}$.btained

$$
E_{D}=4 g(\varepsilon) \mathrm{Pe}^{-2 / 3}
$$

where $g(\varepsilon)$ is a complex function of the porosity $\varepsilon$.

Other flow models to represent a bed of spheres in the creeping motion range ( $\mathrm{Re}_{\mathrm{g}} \rightarrow 0$ ) have been proposed by Kuwabara, ${ }^{21} \mathrm{Tam}_{46}^{41}$ and Neale. and Nader. ${ }^{33}$ These have been reviewed by Tardos et al., ${ }^{43,46}$ and in all cases the single-particle efficiency due to diffusion is represented by an equation of the form (16a) with only the function $g(\varepsilon)$ changing from to model. For porosities in the fluidized bed range $(0.35 \leq \varepsilon \leq 0.7)$ Tardos et al. ${ }^{46}$ recommend the semiempirical expression $g(\varepsilon)=1.31 / \varepsilon$ as a good representation of both the theoretical solutions and the available experimental data, so that Eq. (I6a) becomes

$$
\mathrm{E}_{\mathrm{D}}=5.24 \mathrm{Pe}^{-2 / 3} / \varepsilon
$$

For high particle Reynolds numbers, the flow fields discussed above and Eq. (16b) are not applicable. $\mathrm{Chao}^{5}$ used a potential flow solution for the single-sphere mass transfer problem and obtained, in terms of the Sherwood number;

$$
\mathrm{Sh}=1.13 \mathrm{Pe}^{1 / 2}
$$

Ishii and Johnson ${ }^{1 \overline{7}}$ modified this solution by using the potential flow solution in Lamb. 22 for two concentric spheres to take into account the effect of neighboring particles (porosity effect). Their result, in terms of the single-particle efficiency $E_{D}$, is given by

$$
E_{D}=4.52 \mathrm{Pe}-1 / 2 / \varepsilon^{1 / 2}
$$

Thus Eqs. (16b) and (21) effectively serve to bracket the single-particle efficiency due to diffusion for very low and very high particle Reynolds 
numbers, respectively. Tardos et al. ${ }^{44}$ modified these results slightly to take into account deposition simultaneously by diffusion and by interception (discussed below) by simply applying the boundary condition on the surface of the collector (granule) to include the finite size of the dust particle. This requires, however, a numerical solution for different values of the interception parameter $R_{p}$, namely, the ratio of dust particle size to granule size, $2 \mathrm{r}_{\mathrm{p}} / \mathrm{d}_{\mathrm{g}}$. The single-particle efficiency by diffusion and interception obtained in this manner for $\varepsilon=0.5$ using the Kuwabara flow field is plotted in Figure 3.44

2. Inertial Impaction. Unlike Brownian diffusion, which is prevalent for submicron sized particles and decreases with flow velocity, deposition by inertial impaction is characteristic for particles $>1 \mu \mathrm{m}$ and increases with flow velocity. The mechanism of inertial impaction can be simply explained as follows. The existence of the collector (granule) in the flow causes bending of the gas streamlines near the surface. The particles, because of their inertia, follow the curvature of the streamlines in the vicinity of the collector and are projected against it and separated from the stream. In order to find the conditions for impact of a dust particle and a granule, the trajectory of the dust particle must be computed. Figure 2 shows the limiting or grazing trajectory, defined as the trajectory of a dust particle starting far from the collector and just being captured by a granule. Once this limiting trajectory is known, the single-particle efficiency by inertial impaction can be computed from Eq. (13a).

The trajectory equations for a dust particle approaching a single spherical collector were solved by Herne ${ }^{16}$ using the creeping flow velocity field $\left(\operatorname{Re}_{\mathrm{g}} \rightarrow 0\right)$ and by Michael and Norey ${ }^{32}$ for potential flow $\left(\operatorname{Re}_{\mathrm{g}} \rightarrow \infty\right)$. Paretsky et al. ${ }^{35}$ repeated the solution for creeping flow using the Happel "free surface" model flow field so that the effect of neighboring particles could be taken into consideration. Tardos ${ }^{4 b}$ computed the single-particle efficiency by inertial impaction using the flow fields suggested by Tam, 41 Neale and Nader, ${ }^{33}$ and Kuwabara. ${ }^{21}$ His result, in the form of the singleparticle efficiency $E_{I}$ plotted as a function of the Stokes number defined by $\mathrm{St}=2 \mathrm{C} \rho_{\mathrm{p}} \mathrm{U}_{0} \mathrm{r}_{\mathrm{p}}^{2} / 9 \mathrm{a \mu}$ 
for a porosity $\varepsilon=0.4$, is given in Figure 4 for the flow field of Neale and Nader $\left(\operatorname{Re}_{\mathrm{g}} \rightarrow 0\right)$. Also included in Figure 4 is the solution using the potential flow field and the Kuwabara model for $\mathrm{Re}_{\mathrm{g}} \rightarrow \infty$. Both the creeping flow and the potential flow solutions indicate that no impaction of dust would occur on the collector below a certain critical, value of the Stokes number. The potential flow model also predicts a higher collection efficiency and a lower critical stokes number than the creeping flow model because the gas streamlines are crowded much closer together in potential flow than in creeping flow, as indicated by Figure 5, which shows the velocity profile for each case around a single sphere.

The dimensionless particle trajectory equations that were solved to obtain the results plotted in Figure 4 are

$$
\begin{aligned}
& \frac{d^{2} X}{d t^{2}}=\frac{1}{S t}\left(U_{x}-\frac{d X}{d t}\right)+\frac{\left(\vec{F}_{e x t}\right)}{m_{P}} \frac{a}{U_{0}^{2}}, \\
& \frac{d^{2} Y}{d t^{2}}=\frac{1}{S t}\left(U_{y}-\frac{d Y}{d t}\right)+\frac{\left(\vec{F}_{\text {ext }}\right)}{m_{P}} \frac{a}{U_{0}^{2}},
\end{aligned}
$$

where $\mathrm{d}^{2} \mathrm{X} / \mathrm{dt^{2 }}$ and $\mathrm{d}^{2} \mathrm{Y} / \mathrm{dt^{2 }}$ are the accelerations of the dust particle, $d X / d t$ and $d Y / d t$ are the velocities of the dust particle, $U_{x}$ and $U_{y}$ are the velocity components obtained from a given flow field model, $\mathrm{m}_{\mathrm{p}}$ is the mass of the particle, and the vector $\overrightarrow{\mathrm{F}}_{\text {ext }}$ is the external force acting on the particle. For depositton by inertial impaction $n n 7 y, \vec{F}_{\text {exr }}$ was set equal to zero. If $\overrightarrow{\mathrm{F}}$ ext is set equal to $\mathrm{m}_{\mathrm{p}} \overrightarrow{\mathrm{g}}$ where $\overrightarrow{\mathrm{g}}$ is the acceleration of gravily, then the solution of Eqs. (23) and (24) will give deposition of the particles by a combination of inertial and gravitation effects. The dimensionless group $\mathrm{Ga}^{\prime}=\mathrm{ga} / \mathrm{U}_{0}^{2}$, which results from substitution of $\overrightarrow{\mathrm{F}}$ ext $=\mathrm{m}_{\mathrm{p}} \overrightarrow{\mathrm{g}}$ in Eqs. (23) and (24), is called the Galileo number and is characteristic of gravitational separation. Electrostatic effects could theoretical1y a1so be included in the solution of these equations if a relationship could be developed for the external force due to electrostatic effects on one dust particle moving in a 
bed of granules. As in the case of diffusion, deposition by interception can be superimposed on inertial deposition simply by taking into account the finite size of the dust particle by using a dimensionless effective radius of the granule equal to $1+R_{p}$ instead of the actual radius of the granule in the computations. This was done by Gutfinger et a1. ${ }^{14}$ for both the creeping and potential flow fields for a porosity $\varepsilon=0.5$ (Figure 6).

3. Direct Interception. The mechanism of interception is that a certain amount of dusty gas passes in the vicinity of the collector through the concentric annuli of radii $a$ and $a+r_{p}$, and dust particles carried by the gas through this space touch the granule because of their size $r_{p}$. This happens even when inertial, diffusional, and other deposition effects are negligible and is independent of the velocity of the gas, depending only on the size of the dust particle, $r_{p}$, the size of the granule, $a$, and the porosity of the bed, $\varepsilon$. Interception can be taken into account in combination with diffusion or inertial impaction as discussed above, but for small values of the interception parameter $R_{p}=r_{p} / a$, a separate analytical solution is possible. If it is assumed that the dust particles follow the streamlines of the fluid and a particle is captured only if it passes within a distance $r_{p}$ of the collector surface measured at the angle $\theta=90^{\circ}$ with respect to the direction of flow, then the single-particle efficlency is given by

$$
E_{R}=\frac{\left.\int_{r=a}^{r-a+r} p U_{\theta}\right|_{\theta=\pi} ^{2 \pi r d r}}{U_{0} \pi a^{2}} .
$$

Paretsky et al. ${ }^{35}$ using $\mathrm{U}_{\theta \mid \theta=\pi}$ as given by the Happel ${ }^{15}$ flow field, integrated Eq. (25) to obtain

$$
E_{R}=\frac{3}{2}[g(\varepsilon)]^{3} R_{P}^{2}
$$

and, choosing $g(\varepsilon)=1.31 / \varepsilon$,

$$
E_{R}=3.37 R_{P}{ }^{2} / \varepsilon^{3}
$$




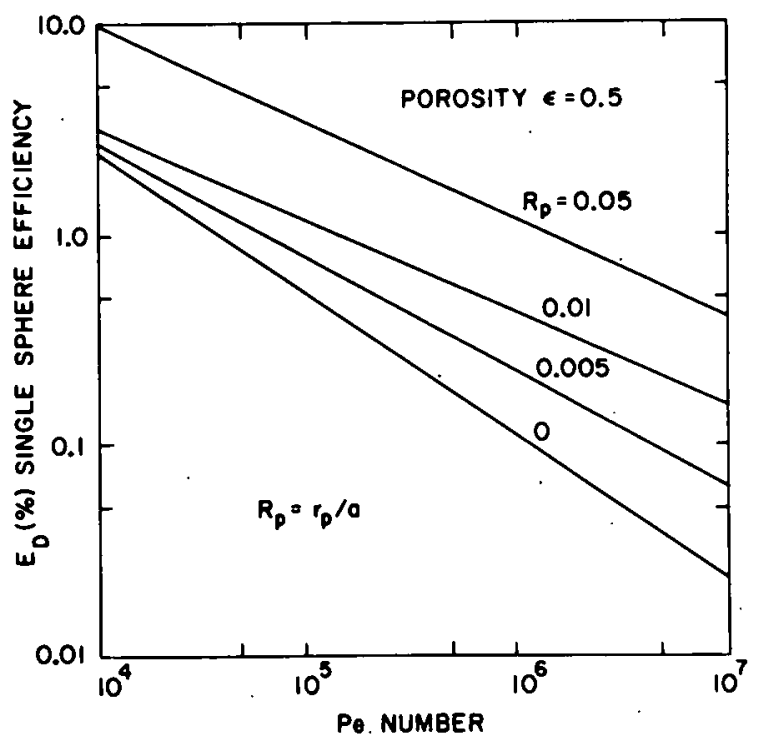

Figure 3. Diffusional capture factor vs. Peclet number for different values of the interception parameter $\left(R_{p}\right)$ in a dense medium. 44

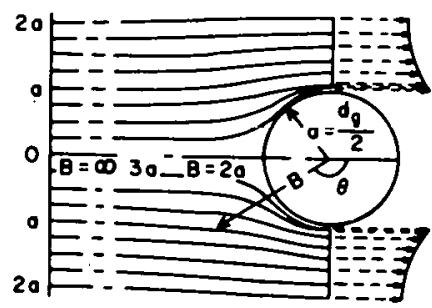

(a) POTENTIAL FLOW

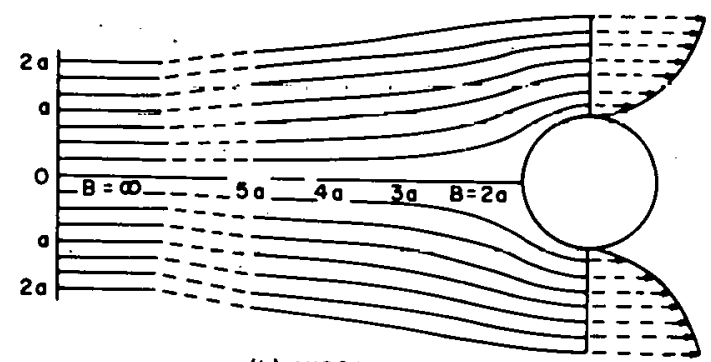

(b) VISCOUS FLOW

Figure 5. Flow lines around a sphere.

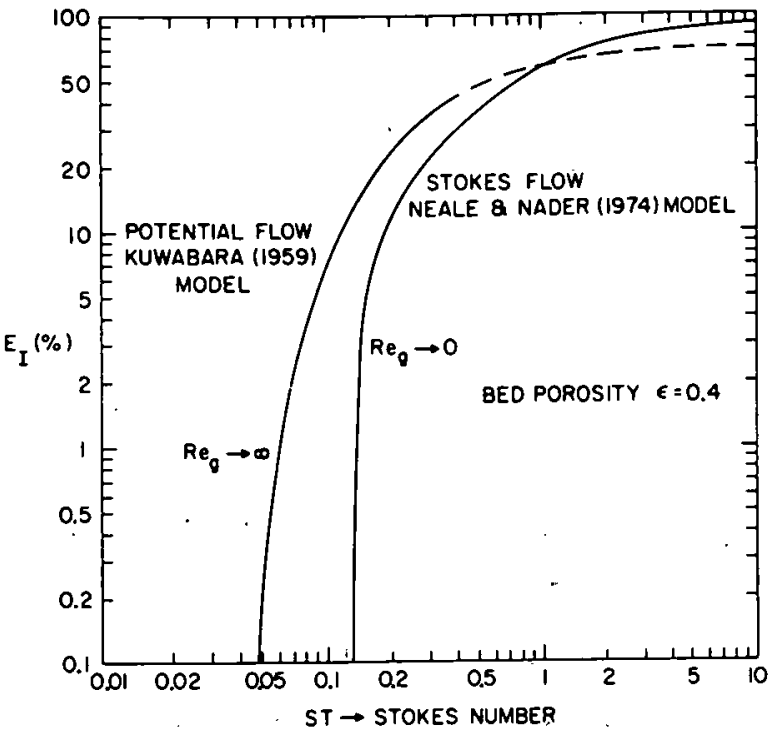

Figure 4. Single-sphere efficiency vs. Stokes number.

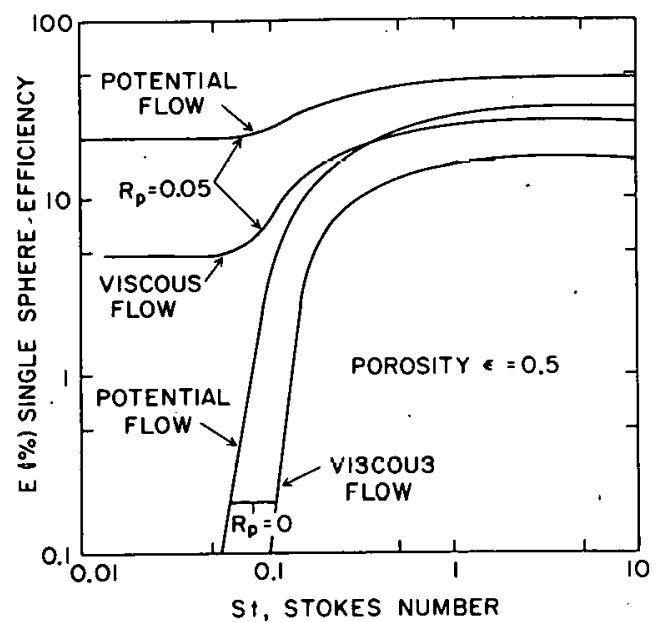

Figure 6. Single-sphere efficiency vs. Stokes number. 14 
With the Lamb ${ }^{22}$ flow field used for flow between two concentric spheres in potential flow, integration of Eq. (24) gives

$$
E_{R}=\frac{1}{\varepsilon}\left[\left(1+2 R_{p}+R_{p}^{2}\right)-\frac{1}{1+R_{p}}\right]
$$

and, for $\mathrm{R}_{\mathrm{p}} \ll 1$,

$$
E_{R}=3 R_{p} / \varepsilon
$$

Thus, although in each case the single-particle efficiency due to interception is independent of gas velocity, the efficiency is much higher for a given value of the interception parameter, $R_{p}$, for potential flow than for creeping flow. This is evident when comparing the two flow fields around a single spherical collector (Figure 5). In general, capture by direct interception is much less than capture by diffusion or inertial impaction.

4. Gravity Settling. As pointed out'above, the trajectory equations, Eqs. (23) and (24), can be used to include any force that can influence the motion of a dust particle in a granular bed. If the external force in the equations is taken as $\overrightarrow{\mathrm{F}}$ ext $=\mathrm{m}_{\mathrm{p}} \overrightarrow{\mathrm{g}}$, gravitational separation (settling) of particles is obtained together with inertial effects. Tardos et $a 1,{ }^{42}$ using the Kuwabara flow model, obtained the combined effect of gravity settling and inertial impaction for a bed of spherical particles of porosity. $\varepsilon=0.5$ (Figure 7). Since gravity acts in the direction opposite to the flow of the gas, the efficiency is greater when gravity settling is not included than when it is. This was verified experimentally by Thomas and Yoder 47 and by Paretsky et al. 35 who found higher filtration efficiencies in packed beds of spherical particles for downward than for upward flow. However, like capture by direct interception, capture by gravity settling is small compared with that by diffusion and inertial impaction, unless the dust particles are very large.

For a single isolated collector (granule), assuming all other collection mechanisms to be negligible, Chen ${ }^{6}$ suggests that the single-particle efficiency due to gravity settling is given by

$$
E_{G}=V_{p} / U_{0}
$$




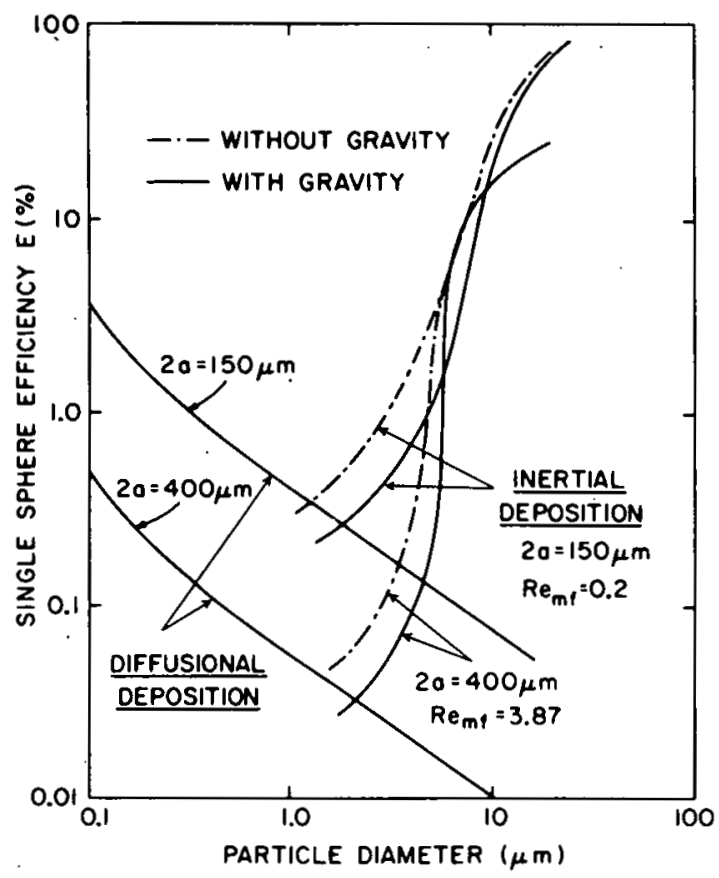

Figure 7. Single-sphere efficiency vs. particle diameter. 42

where $V_{p}$ is the terminal settling velocity of the dust particle. For creeping flow and a spherical dust particle

$$
V_{p}=\frac{2 C\left(\rho_{p}-\rho_{f}\right) r_{p}^{2} g}{9 \mu}
$$

so that Eq. (27) becomes

$$
E_{G}=\frac{2 C\left(\rho_{p}-\rho_{f}\right) r_{p}{ }^{2} g}{9 \mu U_{0}} \text {. }
$$

With the Stokes and Galileo numbers defined as $S t=2 \mathrm{C}_{\rho} \mathrm{U}_{0} \mathrm{r}_{\mathrm{p}}{ }^{2} / 9 \mathrm{a} \mu$ and $\mathrm{Ga}^{-}=\mathrm{ga} / \mathrm{U}_{0}^{2}$, and neglecting $\rho_{\mathrm{f}}$ compared with $\rho_{\mathrm{p}}$, Eq. $(27)$ becomes

$$
E_{G}=S t \mathrm{Ga}^{-}
$$

This is the same expression obtained by Prieve and Ruckenstein ${ }^{38}$ and by Rajagopalan and Tien $^{39}$ for a single isolated collector.

To take into account the effect of neighboring particles in the bed, Paretsky et a1. ${ }^{35}$ multiplied Eq. (27b) by a correction factor equal to 
the average minimum projected area available for flow between the particles, so that

$$
\mathrm{E}_{\mathrm{G}}=\mathrm{K}_{\mathrm{c}} \mathrm{St} \mathrm{Ga}
$$

where $\mathrm{K}_{c}$ is the correction factor, chosen rather arbitrarily as 0.062 . Another way to take gravity settling into account in a bed of particles is simply to replace the superficial velocity $U_{0}$ in Eq. (27) by.the bed velocity, $\mathrm{U}_{0} / \varepsilon$. This gives a correction factor of $\mathrm{K}_{\mathrm{c}}=\varepsilon$.

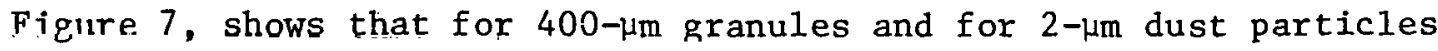
the collection efficiency is $0.031 \%$ with gravity taken into account and $0.055 \%$ without it, so that the effect of gravity is $00.024 \%$. Eq. (27c) gives the single-particle efficiency due to gravity settling as $0.0086 \%$ with $\mathrm{K}_{\mathrm{c}}=0.062$, and as $0.056 \%$ with $\mathrm{K}_{\mathrm{c}}=0.4$.

For very high particle Reynolds numbers, if the drag coefficient is taken as constant and set equal to 0.44 , the terminal settling velocicy of a dust particle is given by

$$
v_{p}=1.74 \sqrt{\rho_{p} / \rho_{f}\left(2 r_{p}\right) g}
$$

so that Eq. (27) becumes

$$
\mathrm{E}_{G}=\frac{1.74 \mathrm{~K}_{\mathrm{e}} \sqrt{\rho_{\mathrm{p}} / \rho_{f}\left(2 \mathrm{r}_{p}\right) \mathrm{g}}}{\mathrm{U}_{0}},
$$

which includes the correction factor $k_{c}$ to take into account that the dust particles are settling in a bed of granules rather than on an isolated collector. Since Eq. (29) 1s appllculle only when the duot particle Reynolds number is very large ( $\operatorname{Re}_{\mathrm{p}} \geq 100$ ), Eq. (27c) will usually be valid for the filtration of micron sized dust particles even at very high gas velocities (potential flow).

\section{B. Overall Filtration Efficiency}

In the preceding section, single-particle collection efficiencies for capture of dust particles in a granular bed of spherical collectors were presented for the mechanisms of Brownian diffusion, inertial impaction, 
direct interception, and gravitational settling. To obtain the total single-particle efficiency when more than one deposition mechanism is operative simultaneously, it is necessary somehow to combine these expressions. One way of doing this, already discussed, is to solve the trajectory equations, Eqs. (23) and (24), for inertial deposition, with interception and gravitational effects taken into account by modifying the equations (adding the gravitational force) or the boundary conditions. Another possibility is simply to add the efficiencies together. The simple empirical equation for the total single-particle efficiency,

$$
E_{T}=E_{D}+E_{I}+E_{R} \text {, }
$$

has been used by Davies, ${ }^{9}$ Pich, ${ }^{37}$ Payatakes et al., ${ }^{34}$ Yao et al., ${ }^{48}$ and others. Davies points out that, since the interception mechanism bridges the region in which either diffusion or inertia predominates, it is reasonable to add the three efficiencies to obtain the total single-particle efficiency. Eq. (30) is, however, at best an approximation and must be used cautiously since it can give overly high efficiencies, especially when gravitational settling and/or electrostatic capture are also significant and are included in the summation.

If the total single-particle efficiency can be estimated from Eq. (30) or otherwise, then the overall filtration efficiency for the granular bed, $n$, can be calculated by using an equation derived both by Paretsky et al. 35 and by Tardos et al., 42

$$
\eta=1 \operatorname{cxp}\left[-1.5 E_{\hat{\mathrm{T}}} \frac{(1-\varepsilon)}{\varepsilon} \frac{L}{2 \mathrm{a}}\right]
$$

where $\mathrm{L}$ is the thickness or height of the granular bed and $\varepsilon$ is its voidage. This expression for the overall efficiency is very similar to the one commonly used for cylindrical fiber filters, 12,37 and assumes that filter elements situated in the same layer (L/2a) exhibit similar separation propertles dud Lhal the dust conccntration at the exit and entrance of each layer is uniform. Eq. (31) shows the important effect of filter thickness $L$ on filtration efficiency. Thus, increasing the filter thickness may 
dramatically improve filtration efficiencies even for the case of very low single-particle efficlencies.

In Figures 8 and 9 , from Tardos et al.,$^{46}$ the overall filtration efficiency computed from Eq. (31) is compared with experimental filter bed efficiencies. Figure 8 shows limited data from Paretsky ${ }^{35}$ on a packed bed filter and data from Knetting and Beeckmans ${ }^{19}$ on a fluidized bed filter. In Figure 9 the theory is compared with experimental data obtained by Tardos 45 under conditions carefully controlled to keep electrostatic charge effects negligible. In both figures the fit between the theory and experimental data is quite good. Experimental data obtained where electrostatic effects were not negligible indicated efficiencles much higher than those theoretically predicted (an example of such data is presented in a later section).

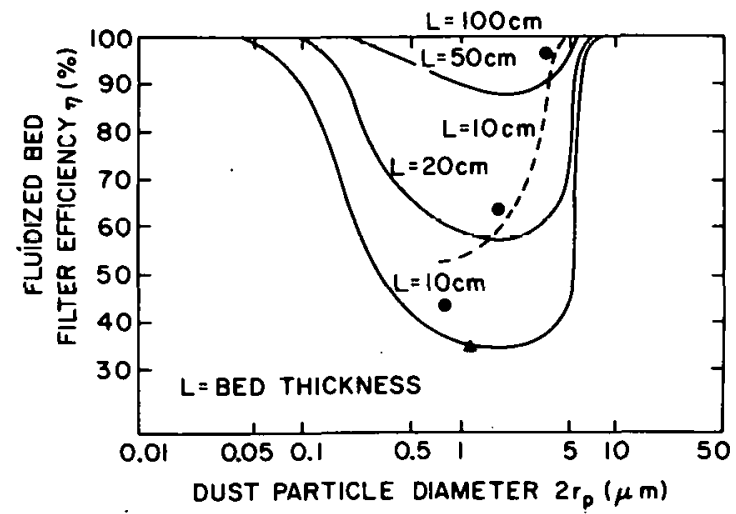

Figure 8. Fluldized bed filter efficlency vs. dust particle diameter. 46 - filter porosity $\varepsilon=0.5$, sphere diam. $2 \mathrm{a}=400 \mu \mathrm{m}$, gas velocity $\mathrm{U}_{0}=$ $13 \mathrm{~cm} / \mathrm{sec}:-\cdots, \varepsilon=0.38,2 \mathrm{a}=475 \mathrm{~lm}, \|_{0}=11.2 \mathrm{~cm} / \mathrm{sec}$. A, Paretcly et al.35 experiment: $U_{n}=13.3 \mathrm{~cm} / \mathrm{sec}, L=8.2 \mathrm{~cm}, 2 a=500.1850 \mathrm{um}$. $\varepsilon_{0}=$ 0.43 ; $\bullet$ Knetting and Beekmans 19 experiment: screen supported bed, $\mathrm{U}_{0}=11.2 \mathrm{~cm} / \mathrm{sec}, \mathrm{L}=10 \mathrm{~cm}, 2 \mathrm{a}=425 \mu \mathrm{m}, \varepsilon=0.38$.

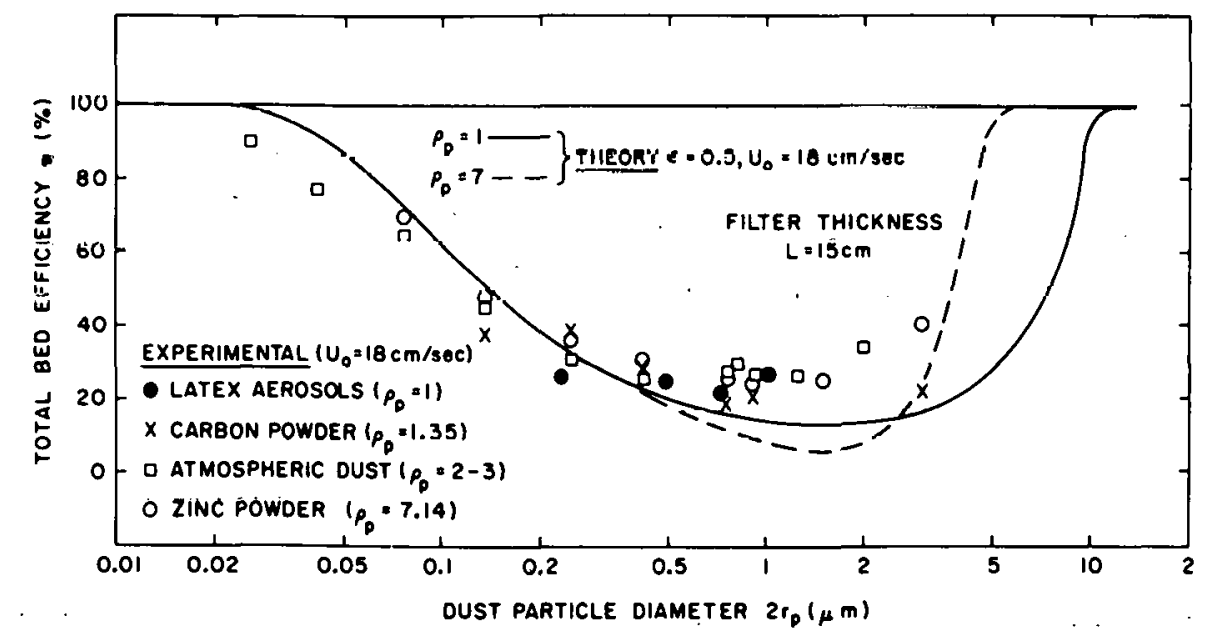

Figure 9. Total filter efficlency vs. dust particle diameter in a $t$ In bed of $690-\mu \mathrm{m}$ granules (porosity $\varepsilon=0.5$ ). 46 
A striking feature of the curves in Figures 8 and 9 is the large dip in overall filtration efficiency at values of the dust particle diameter in the range 0.1 to $5 \mu \mathrm{m}$. The location of the dip and the value of the overall filtration efficiency there are functions of granule diameter, gas velocity, and filter bed thickness. Thus a granular bed filter cannot be characterized by an overall efficiency of say, $99 \%$. The efficiency varies with the size of the dust being filtered, but it can be safely said that granular bed filters are very efficient in filtering dust of sizes $>5 \mu \mathrm{m}$ and $<0.1 \mu \mathrm{m}$.

\section{THE ROTATING FLUIDIZED BED AS A DUST FILTER}

In this section a numerical example is used to compare the performance of a conventional fluidized bed with that of a rotating fluidized bed as a dust filter. Assume a conventional fluidized bed of granule diameter $\mathrm{d}_{\mathrm{g}}=0.5 \mathrm{~mm}$, granule density $\rho_{\mathrm{g}}=2.5 \mathrm{~g} / \mathrm{cm}^{3}$, and porosity $\varepsilon=0.4$. The minimum fluidization velocity, $\mathrm{U}_{\mathrm{mf}}$, depends on the value of $\mathrm{Re}_{\mathrm{g}}$. Assume $\operatorname{Re}_{\mathrm{g}}<20$ and use Eq. (9) to calculate $U_{\mathrm{mf}}$, replacing $\omega_{0}^{2} r$ by $g$, the acceleration of gravity:

$$
\mathrm{U}_{\mathrm{mf}}=\mathrm{d}_{\mathrm{g}}{ }^{2}\left(\frac{\rho_{\mathrm{g}}}{\rho_{\mathrm{f}}}-1\right) \frac{\mathrm{g}}{1650 \mathrm{v}} .
$$

Taking $v=0.18 \mathrm{~cm}^{2} / \mathrm{sec}$,

$$
U_{\mathrm{mf}}=\frac{(0.05)^{2}(2499) 980}{1650 \times 0.18}=20.6 \mathrm{~cm} / \mathrm{sec} \quad \text { or } \quad \sim 20 \mathrm{~cm} / \mathrm{sec} \text {. }
$$

The grain Reynolds number is

$$
\operatorname{Re}_{g}=\frac{0.05 \times 20.6}{0.18}=5.7 \text { or } \quad<20 \text {. }
$$

The pressure drop per unit thickness or length of bed is computed from Eq. (2), again w1th a replaced by $g$ :

$$
\begin{aligned}
& \Delta P / L=(1-\varepsilon)\left(\rho_{g}-\rho_{f}\right) g \\
& \frac{\Delta P}{L}=0.6(2.5) 980=\frac{1470 \text { dynes } / \mathrm{cm}^{2}}{\mathrm{~cm}}=1.5 \frac{\mathrm{cm} \text { water }}{\mathrm{cm} \text { bed }} .
\end{aligned}
$$


The main disadvantage of using a conventional fluidized bed as a dust filter, as discussed in the Introduction, is the limitation of the gas velocity to about $50 \%$ above the minimum fluidization velocity. In any industrial filter this would require the filter area to be excessively large. In the rotating fluidized bed the velocity in the bed can be raised to much higher levels by increasing the rotational speed (g-loading). Assume, for example, a rotating bed operating at a velocity 20 times as great as the minimum fluidization velocity of the conventional fluidized bed, i.e., 400 $\mathrm{cm} / \mathrm{sec}$. This gives a grain Reynolds number

$$
R_{g}=\frac{0.5 \times 400}{0.18}-111
$$

Assume a bed thickness $\mathrm{L}=5 \mathrm{~cm}$ and an outer radius $\mathrm{r}_{0}=12.5 \mathrm{~cm}$, and evaluate the Galileo number at $r=r_{0}$ by using Eq. (6a):

$$
\begin{aligned}
& \mathrm{Ga}=\frac{\mathrm{d}}{v^{2}}\left(\frac{\rho_{\mathrm{g}}}{\rho_{\mathrm{f}}}-1\right) \omega_{\mathrm{o}}^{2} \mathrm{r}_{\mathrm{o}}, \\
& \mathrm{Ga}=\frac{(0.05)^{3}}{(0.18)^{2}}(2499) \omega_{0}^{2}\left(125=121 \omega_{0}^{2} .\right.
\end{aligned}
$$

At a minimum fluidization velocity of $400 \mathrm{~cm} / \mathrm{sec}$

$$
\operatorname{Re}_{\text {LF }}=111 .
$$

Substituting into Eq. (8) and solving for the Galileo number gives.

$$
\begin{aligned}
\operatorname{Re}_{\mathrm{mf}} & =\left[(33.7)^{2}, 0.0408 \mathrm{Ga}\right]^{1 / 2} 33.7, \\
111 & =\left[(33.7)^{2}+0.0408 \mathrm{~F}_{\mathrm{a}}\right]^{1 / 2}-33.7, \\
\mathrm{Ga} & =4.85 \times 10^{5} .
\end{aligned}
$$

But Ga $=121 \omega_{0}^{2}$, so that

$\omega_{0}=63.3 \mathrm{radians} / \mathrm{sec}$. 
At this rotational speed the g-loading is

$$
\frac{\omega_{0}^{2} r_{0}}{g}=\frac{(63.3)^{2} \times 12.5}{980}=51 \mathrm{~g} .
$$

This is roughly at the upper limit of the range of radial accelerations (10 to $50 \mathrm{~g}$ ) used in recent rotating fluidized bed designs.

Use of the simplified Eq. (9) to calculate the rotational speed gives

$$
400=\frac{(0.05)^{2}(2499) \omega_{0}^{2} 12.5}{1650 \times 0.18} \text { or } \quad \omega_{0}=39 \mathrm{radians} / \mathrm{sec} .
$$

This is an appreciable difference from the 63.3 radians/sec calculated from Eq. (8) and indicates that Eq. (9.) cannot be used at a grain Reynolds numbers, $\operatorname{Re}_{\mathrm{g}}=111$, which is $>20$.

Calculation of the bed pressure drop from Eq. (4) gives

$$
\begin{aligned}
& \Delta P=(1-\varepsilon)\left(\rho_{g}-\rho_{f}\right) \omega_{o}^{2}\left(r_{o}^{2}-r_{i}^{2}\right) / 2, \\
& \Delta P=0.6(2.5)(63.3)^{2}\left[(12.5)^{2}-(7.5)^{2}\right] / 2, \\
& \Delta P=3.01 \times 10^{5} \text { dynes } / \mathrm{cm}^{2},
\end{aligned}
$$

and

$$
\frac{\Delta \mathrm{P}}{\mathrm{L}}=\frac{3.01 \times 10^{5}}{5 \times 980}=61.3 \frac{\mathrm{cm} \text { water }}{\mathrm{cm} \text { bed }}
$$

Use of Eq. (3) to calculate the pressure drop gives

$$
\begin{aligned}
& \Delta \mathrm{P}=(1-\varepsilon)\left(\rho_{\mathrm{g}}-\rho_{\mathrm{f}}\right) \omega_{\mathrm{o}}{ }^{2} \mathrm{r}_{\mathrm{o}}{ }^{2} \ln \left(\mathrm{r}_{\mathrm{o}} / \mathrm{r}_{\mathrm{i}}\right), \\
& \Delta \mathrm{P}=0.6(2.5)(63.3)^{2}(12.5)^{2} \ln (12.5 / 7.5), \\
& \Delta \mathrm{P}=4.80 \times 10^{5} \text { tynes } / \mathrm{cm}^{2},
\end{aligned}
$$

and

$$
\frac{\Delta P}{L}=\frac{4.80 \times 10^{5}}{5 \times 980}=98.0 \frac{\mathrm{cm} \text { water }}{\mathrm{cm} \text { bed }}
$$


Thus, for a 5-cm-thick bed, Eqs. (3) and (4) give appreciably different results for bed pressure drop. Comparison of the result of Eq. (4), which is equivalent to assuming the pressure drop to be equal to the weight of the rotating fluidized bed per unit area of the distributor, Eq. (4a), with the pressure drop in the conventional fluidized bed shows that increasing the velocity by a factor of 20 increases the pressure drop per unit thickness across the bed by a factor of 240 and requires a g-loading about 50 times the acceleration of gravity.

Since the rotating fluidized bed in this example operates at a g-loading 50 times the acceleration of gravity, the first thing to be determined is whether the single-particle efficiency due to gravitational settling, unlike that in a conventional fluidized bed; becomes an important mechanism of deposition in a rotating fluidized bed filter. From Eq. (27c), the singleparticle efficiency due to gravity settling is given by.

$$
\mathrm{E}_{\mathrm{G}}=\mathrm{K}_{\mathrm{c}} \mathrm{St} \mathrm{Ga}
$$

where $S t=2 C \rho_{p} U_{0}{ }_{p}^{2} / 9 a \mu$ and $\mathrm{Ga}^{\prime}=g a / \mathrm{U}_{0}{ }^{2}$. Replacing $\mathrm{U}_{0}$ by the minimum fluidization velocity $U_{m f}$ and $g$ by the radial acceleration, $a_{r}=\omega_{0}{ }^{2}$, gives

$$
E_{G}=\frac{2 K_{c} C \rho p{ }^{r}{ }^{2}{ }^{2} \omega_{0}{ }^{2} r}{9 \mu U_{m f}} .
$$

For low grain Reynolds numbers (creeping motion $r$ ange) $U_{\mathrm{mf}}$ is evaluated by using Eq. (9) so that Eq. (32) becines

$$
E_{G}=\frac{2}{9} K_{c} \operatorname{Cx1650}\left(\frac{x_{p}}{d_{y}}\right)^{2} \frac{\rho_{p}}{\rho_{g}-\rho_{f}}
$$

and, with $\rho_{p}=2.0$ and $\rho_{g}=2.5$, the result is

$$
E_{G}=73.3 \mathrm{CK}_{C_{p}}^{2}
$$

where $R_{p}$ is the interception parameter previously defined as $R_{p}=2 r_{p} / d_{g}$. 
For very high grain Reynolds numbers (potential flow), $\mathrm{U}_{\mathrm{mf}}$ in Eq. (32). is defined by Eq. (10):

$$
U_{m f}=0.2 \sqrt{d_{g}\left(\frac{\rho_{g}}{\rho_{f}}-1\right) \omega_{o}^{2} r} .
$$

For $r=r_{0}, E q . \quad(32)$ becomes

$$
E_{G}=61.8 C K_{c} \frac{\left(2 r_{p}\right)^{2}}{U \sqrt{d}}\left(\omega_{o}{ }^{2} r_{o}\right)^{1 / 2}
$$

and, with $\omega_{0}=63.3 \mathrm{radians} / \mathrm{sec}, \mathrm{r}_{\mathrm{o}}=12.5 \mathrm{~cm}$, and $\mathrm{d}_{\mathrm{g}}=0.05 \mathrm{~cm}$,

$$
E_{G}=61.8 \times 10^{3} \mathrm{CK}_{\mathrm{c}}\left(2 \mathrm{r}_{\mathrm{p}}\right)^{2}
$$

Equation ( $32 \mathrm{~b}$ ) indicates that in the creeping flow regime deposition by gravitational settling in the rotating fluidized bed is independent of rotational speed and depends only on the interception parameter $R_{p}$. This is because increasing the $g$ force causes an increase in the settling velocity of the dust particle, but also causes a corresponding increase in the minimum fluidization velocity of the bed. In the potential flow regime, however, deposition by gravitational settling is a function of the square root of the radial acceleration and therefore varies with the rotational speed of the bed.

Table 1 gives values of the single-particle gravitational settling efficiency as a function of dust particle size, $2 r_{p}$, for the case being considered, with use of either Eq. (32b) or Eq. (32d) and an arbitrary value of $\mathrm{K}_{\mathrm{c}}=0.062$.

The data indicate that in both the creeping motion and the potential flow regimes the single-particle efficiency due to gravitational deposition in the rotating fluidized bed, $a \varepsilon$ in a conventional fluidized bed, is very small for dust particles in the size range 0.1 to $4.0 \mu \mathrm{m}$. Since the radial acceleration acts opposite to the direction of flow of the gas, the gravitational deposition tends to lower the single-particle efficiency. However, because of the small efficiencies calculated in Table 1, the uncertainty 
Table. 1

Single-Particle Efficiency for Gravitational Deposition

\begin{tabular}{|c|c|c|c|c|}
\hline $2 r_{p}(\mu m)$ & C & $\mathrm{R}_{\mathrm{P}}^{2}$ & $\mathrm{E}_{\mathrm{G}}$ & $\mathrm{E}_{\mathrm{G}}(\%)$ \\
\hline \multicolumn{5}{|c|}{ Creeping Flow Regime, Eq. (32b) } \\
\hline $\begin{array}{l}0.1 \\
0.5 \\
1.0 \\
4.0\end{array}$ & $\begin{array}{l}3.05 \\
1.33 \\
1.16 \\
1.04\end{array}$ & $\begin{array}{r}4 \times 10^{-8} \\
10^{-6} \\
4 \times 10^{-6} \\
6.4 \times 10^{-5}\end{array}$ & $\begin{array}{l}5.6 \times 10^{-7} \\
6.1 \times 10^{-6} \\
2.1 \times 10^{-5} \\
3.1 \times 10^{-4}\end{array}$ & $\begin{array}{l}5.6 \times 10^{-5} \\
6.1 \times 10^{-4} \\
2.1 \times 10^{-3} \\
3.1 \times 10^{-2}\end{array}$ \\
\hline \multicolumn{5}{|c|}{ Potential Flow Regime, Eq. (32d) } \\
\hline $\begin{array}{l}0.1 \\
0.5 \\
1.0 \\
4.0\end{array}$ & $\begin{array}{l}3.05 \\
1.33 \\
1.16 \\
1.04\end{array}$ & $\begin{array}{r}10^{-10} \\
1.3 \times 10^{-9} \\
10^{-8} \\
1.6 \times 10^{-7}\end{array}$ & $\begin{array}{l}1.2 \times 10^{-6} \\
1.3 \times 10^{-5} \\
4.4 \times 10^{-5} \\
6.3 \times 10^{-4}\end{array}$ & $\begin{array}{l}1.2 \times 10^{-4} \\
1.3 \times 10^{-3} \\
4.4 \times 10^{-3} \\
6.3 \times 10^{-2}\end{array}$ \\
\hline
\end{tabular}

of the value of $\mathrm{K}_{c}$, and the questionable legitimacy of including $\mathrm{E}_{\mathrm{G}}$ as another term in Eq. (30) to obtain the total single-particle efficiency, this term will be neglected, and only deposition by diffusion, inertial impaction, and interception will be considered.

The single-particle efficiency due to diffusion, inertial impaction, and interception is computed below for dust particle sizes 0.1 to $4.0 \mu \mathrm{m}$ for both creeping flow ( $\left.\operatorname{Re}_{g} \rightarrow 0\right)$ and potential flow $\left(\operatorname{Re}_{g} \rightarrow \infty\right)$ with use of the equations developed in Section III. Since the actual grain Reynolds number for both the conventional and the rotating fluldized bed is of finfte size between these limits, the results will tend to bracket the actual expected efficiencies.

For diffusion in the creeping motion regime, Eq. (16b) is used,

$$
E_{D}=5.24 \mathrm{Pe}^{=2 / 3} / \varepsilon \text {, }
$$

with the Peclet number defined by Eq. (17), the diffusion coefficient by Eq. (18), and the Cunningham correction factor by Eq. (19), and with the Boltzmann constant $=1.38 \times 10^{-16} \mathrm{ergs} /{ }^{\circ} \mathrm{K}$ and a bed voidage $\varepsilon=0.4$.

Equation (18) can be written as

$$
D=2.42 \times 10^{-7} / .2 \mathrm{r} p
$$


where $2 r_{p}$ is the dust particle diameter in microns, and it can be conveniently used to calculate the diffusion coefficient appearing in the Peclet number. Single-particle efficiencies (as percent) were calculated with Eq. (16b) and plotted versus the superficial velocity in the bed for dust particles of size $0.1,0.5,1.0$, and $4.0 \mu \mathrm{m}$ (Figures 10 to 13 ). The curves are all straight lines of slope equal to $-2 / 3$ on the $\log$ plots and clearly show that the efficiency due to diffusion is largest for small particles and decreases as the dust particle size and velocity in the bed increase.

For direct interception in the creeping motion regime, Eq. (25b) is used,

$$
E_{R}=3.37 R_{p}^{2} / \varepsilon^{3}
$$

and, for $\varepsilon=0.4$,

$$
\mathrm{E}_{\mathrm{R}}=52.7 \mathrm{R}_{\mathrm{P}}^{2}
$$

Calculated values of $E_{R}$ are given in Table 2. They are significant only for particle sizes of 1 and $4 \mu \mathrm{m}$ and appear in Figures 12 and 13 as horizontal lines independent of velocity.

\begin{tabular}{crcr}
\hline \multicolumn{5}{c}{ Table } \\
Single-Particle Efficiency for Direct Interception, Re $\rightarrow 0$ \\
\hline $2 \mathrm{r}_{\mathrm{p}}(\mu \mathrm{m})$ & $\mathrm{R}_{\mathrm{p}}{ }^{2}$ & $\mathrm{E}_{\mathrm{R}}$ & $\mathrm{E}_{\mathrm{R}}(\%)$ \\
\hline 0.1 & $4 \times 10^{-8}$ & $2.11 \times 10^{-6}$ & $2.11 \times 10^{-4}$ \\
0.5 & $40^{-6}$ & $5.27 \times 10^{-5}$ & $5.27 \times 10^{-3}$ \\
1.0 & $4 \times 10^{-6}$ & $2.11 \times 10^{-4}$ & $2.11 \times 10^{-1}$ \\
4.0 & $6.4 \times 10^{-5}$ & $3.37 \times 10^{-3}$ & $3.37 \times 10^{-1}$ \\
\hline
\end{tabular}

For inertial impaction, the $\mathrm{Re} \rightarrow 0$ curve in Figure 4 (a plot of singleparticle efficiency vs. Stokes number) is used to calculate single-particle efficiency as a function of superficial bed velocity for each particle size considered. As seen in Figure 4, deposition by inertial impaction is zero below a critical value of the stokes number. For dust particles of sizes 0.1 and $0.5 \mu \mathrm{m}$ the critical Stokes number has not yet been reached at superficial bed velocities of up to $1000 \mathrm{~cm} / \mathrm{sec}$, so that inertial impaction does 


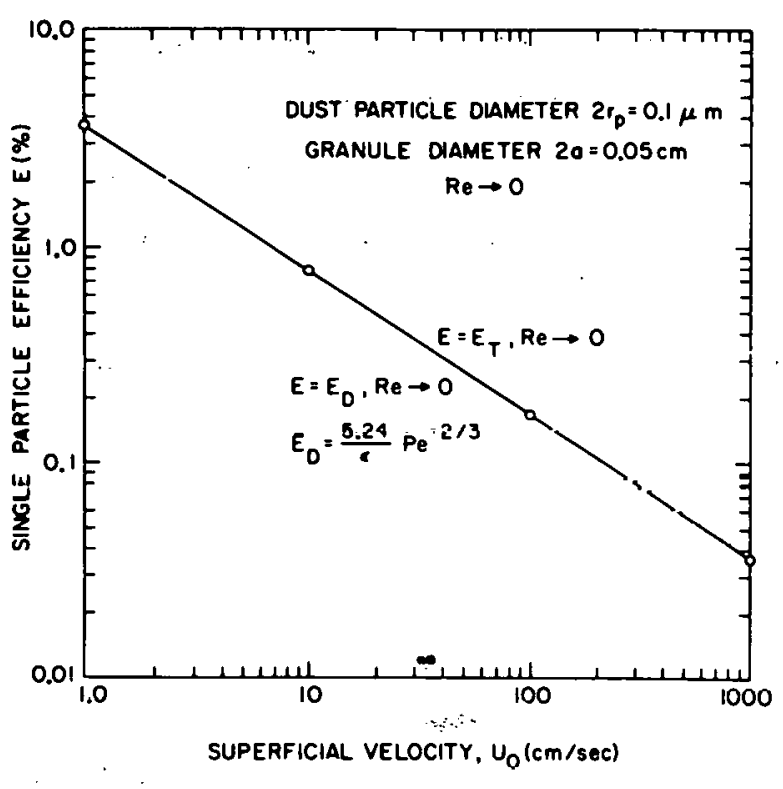

Figure 10. Variation of singleparticle filtration efficiency with velocity.

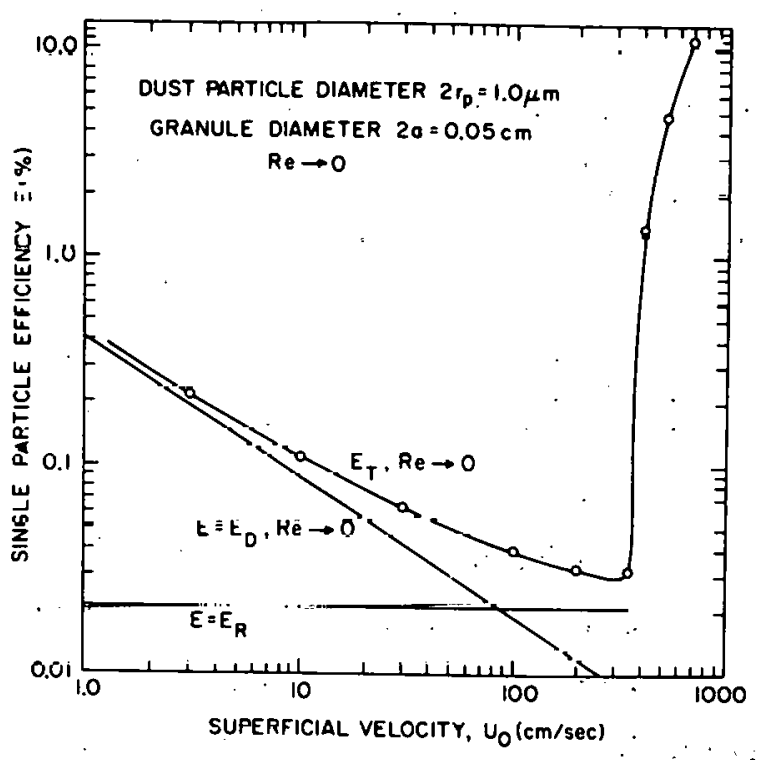

Figure 12. Variation of singleparticle filtration efficiency with velocity.

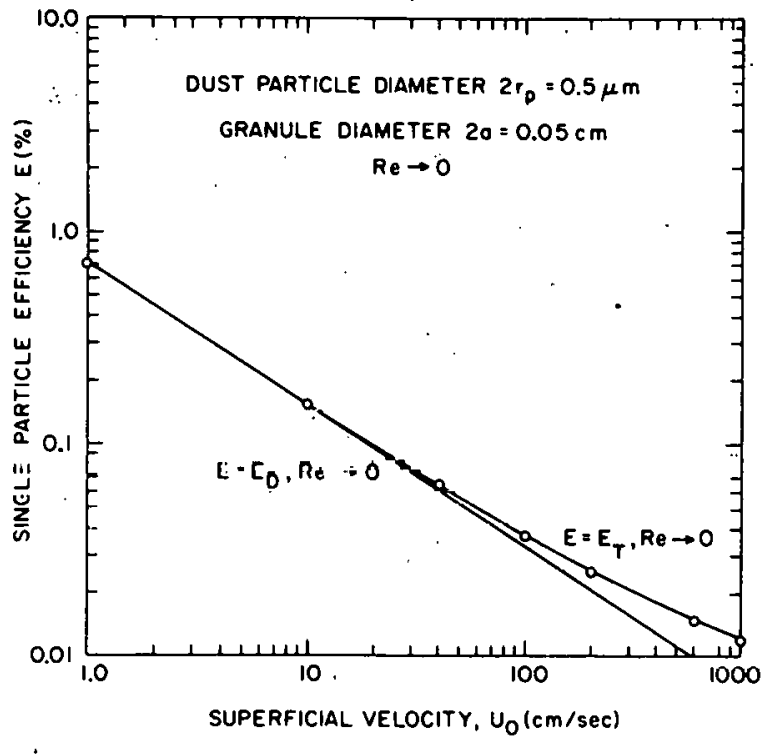

Figure 11. Variation of singleparticle filtration efficiency with velocity.

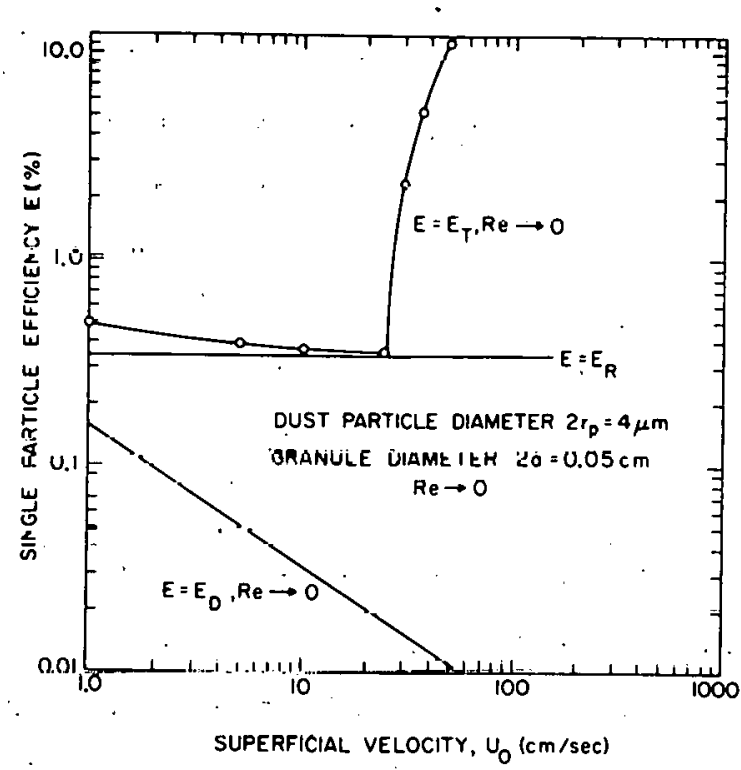

Figure 13. Variation of singleparticle filtration efficiency with velocity. 
not contribute to the filtration efficiency, and the total single-particle efficiencies plotted in Figures 10 and 11 are for diffusion and impaction only. For dust particles of sizes 1.0 and $4: 0 \mu \mathrm{m}$, inertial impaction becomes important in the velocity range of interest, and its effect is seen in the rapidly rising portion of the total single-particle efficiency curves in Figures 12 and 13. In Figures 10 through 13 the total single-particle efficiency. was calculated by the simple summation rule, Eq. (30).

For potential flow, the single-particle efficiency due to diffusion was calculated by using Eq. (21),

$$
E_{D}=4.52 \mathrm{Pe}^{-1 / 2} / \varepsilon^{1 / 2}
$$

The single-particle efficiency due to interception was calculated by using Eq. (26a),

$$
\mathrm{E}_{\mathrm{R}}=3 \mathrm{R}_{\mathrm{p}} / \varepsilon^{\prime}
$$

and, for $\varepsilon=0.4$,

$$
E_{R}=7.5 R_{p}
$$

Table 3

Single-Particle Efficiency for Direct Interception, $\mathrm{Re} \rightarrow \infty$

\begin{tabular}{cccc}
\hline $2 \mathrm{r}_{\mathrm{p}}(\mu \mathrm{m})$ & $\mathrm{R}_{\mathrm{p}}$ & $\mathrm{E}_{\mathrm{R}}$ & $\mathrm{E}_{\mathrm{R}}(\%)$ \\
\hline 0.1 & $2 \times 10^{-4}$ & $1.5 \times 10^{-3}$ & 0.15 \\
0.5 & $10^{-3}$ & $7.5 \times 10^{-3}$ & 0.75 \\
1.0 & $2 \times 10^{-3}$ & $15 \times 10^{-3}$ & 1.5 \\
4.0 & $8 \times 10^{-3}$ & 0.06 & 6.0 \\
\hline
\end{tabular}

The results, summarized in Table 3 , are seen to be much higher than those for creeping flow (Table 2). The single-particle pfficiency by inertial impaction was obtained by using the $R e \rightarrow \infty$ curve in Figure 4. Figures 14 through 17 are plots of the single-particle efficiency for diffusion and for direct interception and of the total obtained by the simple summation rule, Eq. (30). 


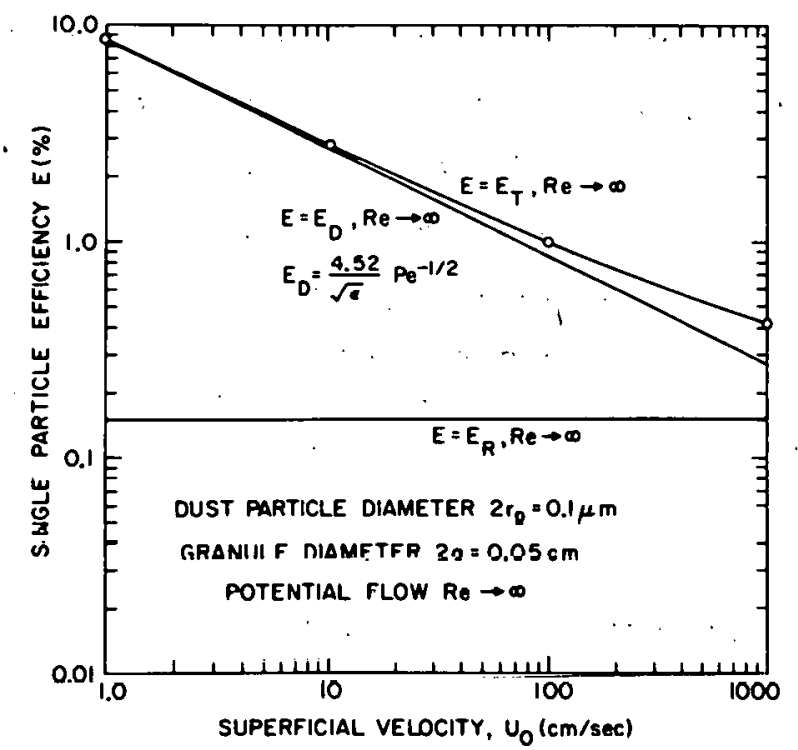

Figure 14. Variation of singleparticle filtration efficiency with velocity.

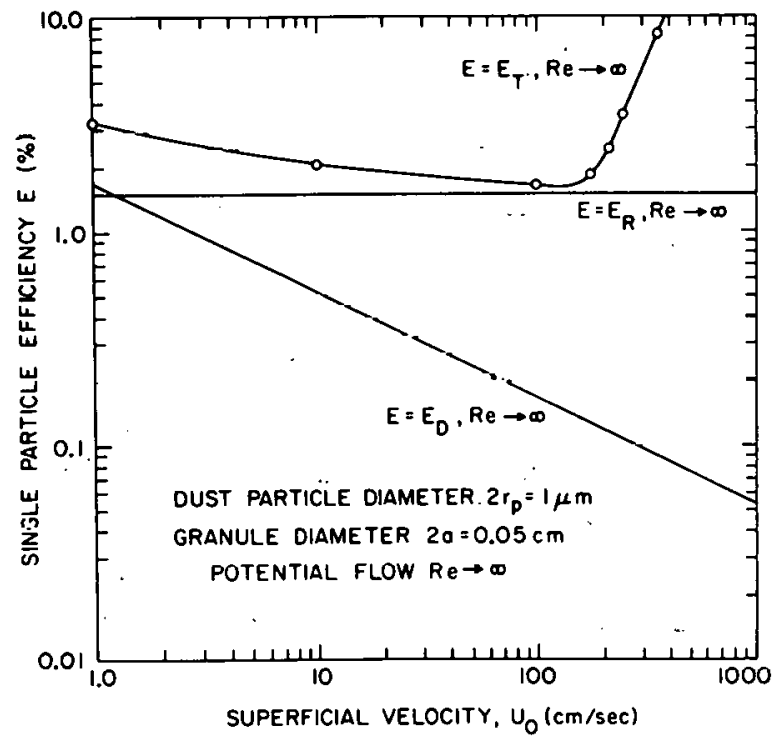

FIgure 16. Variation of singleparticle filtration efficiency with velocity.

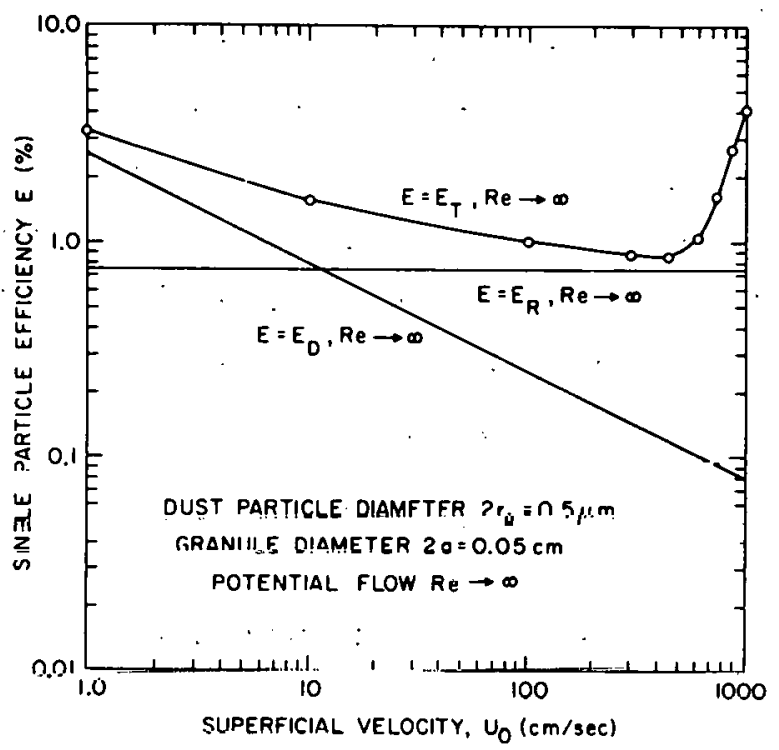

Figure 15. Variation of singleparticle filtration efficiency with velocity.

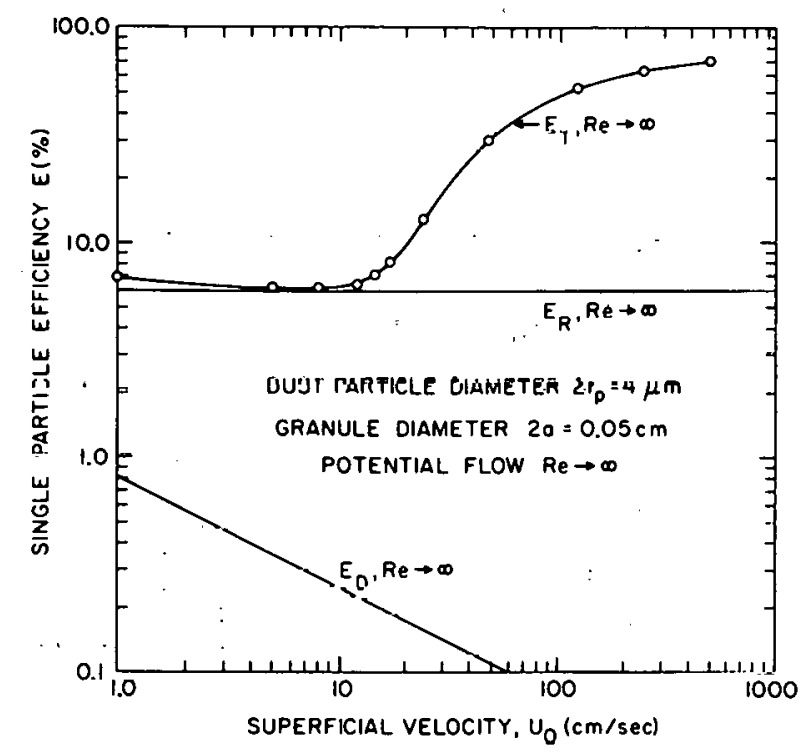

Figure 17. Variation of singleparticle filtration efficiency with velocity. 
The results for total single-particle efficiency in. Figures 10 through 17 were used to plot total single-particle efficiency against dust particle size for superficial velocities of 30 and $400 \mathrm{~cm} / \mathrm{sec}$, for both creeping and potential flow (Figure 18). For a superficial velocity of $30 \mathrm{~cm} / \mathrm{sec}$, representing operating conditions in a conventional fluidized bed at 1.5 times the minimum fluidization velocity, the lower curve $(\operatorname{Re} \rightarrow 0)$ is more applicable because the grain Reynolds number is very low $(<10)$. For the rotating fluidized bed operating at a superficial velocity of $400 \mathrm{~cm} / \mathrm{sec}$, the grain Raynolds number was calculated to be ill; therefore, the proper efficiency vs. dust particle diameter curve lies somewhere between the two limiting curves representing creeping flow and potential flow.

The overall bed efficiency $n$ was calculated from the total singleparticle efficiency by using Eq. (31) with an assumed bed thickness $L=5 \mathrm{~cm}$. The results for a rotating fluidized bed operating at a minimum fluidization velocity of $400 \mathrm{~cm} / \mathrm{sec}$ are presented in Figure 19 for the two limiting cases of creeping motion $(\operatorname{Re} \rightarrow 0)$ and potential flow $(\operatorname{Re} \rightarrow \infty)$. The actual curve for a Reynolds number of 111 should lie somewhere. in between. The data in Figure 19 indicate that a rotating fluidized bed operating at the conditions chosen for this numerical example should serve as an excellent filter, with efficiencies that are very high in the entire spectrum of dust particle sizes and approach $100 \%$ for particles $>1 \mu \mathrm{m}$.

The overall filtration efficiencies actually obtained in a rotating fluidized bed could be lower than those predicted by Figure 19 since the theoretical analysis did not take into account the possibility of reentrainment of dust particles once they lave been captured by the granules in the filter. This did not seem to occur in experiments in conventional fluidized bed filters, as shown by the good agreement between the experimental data and the theoretical predictions in Figures 8 and 9 . However, the much higher operating velocity ( 400 rather than $30 \mathrm{~cm} / \mathrm{sec}$ ) as well as the effect of the tangential velocity imparted to the gas in the rotating fluidized bed could cause appreciable dust reentrainuent and a corresponding drop in overall efficiency. Whether this will occur in practice can be determined only by experiments. 
On the other hand, the theoretical analysis also neglected deposition of dust due to electrostatic effects, which could greatly enhance the overall filtration efficiency. Tardos ${ }^{45}$ found that a fluidized bed filter with Lucite spheres as the granules for filtering cement dust gave filtration efficiencies much higher than expected from theoretical predictions (Figure 20). He found that the discrepancy between theory and experiment was due to the Lucite bed being electrostatically charged, and that the amount of charge could be increased by vigorous fluidization of the bed with dry aix before or during the filtration experiment or decreased by passing very humid air at low velocity through the bed to remove the charge. The filtration efficiency of the fluidized bed filter showed a large increase Immediately after the gas velocity exceeded the minimum fluidization velocity (Figure 21); this indicated that fluidization causes the dielectric plastic granules to acquire electrostatic charges by contact or frictional electrification, a phenomenon known as triboelectrification. Further increases in gas velocity above minimum fluidization cause a decrease in efficiency due to bubbles formed in the bed and the bypassing of dust via the bubble phase. The large increase in efficiency observed in the fluidized bed was not found in a packed bed of sand granules run at the same operating conditions (Figure 21). Anderson and Silverman ${ }^{l}$ noted the importance of triboelectrification in fluidized bed filters as early as 1958, and found that electric charge is generated within a fluidized bed because of contacts of the fluidized media with conducting surfaces interspersed throughout the media; in one series of tests they noted a 12-fold increase in collection efficiency due to the use of electrostatically charged filter media. Recently Figueroa and Licht ${ }^{1 I^{\prime}}$ obtained very high collection efficiencies $(\geq 99 \%)$ by using relatively shallow $(\leqslant 9 \mathrm{~cm})$ fluidized beds of plastic beads for filtering aerosols in the 0.5 to 2.0-um size ranges; they attributed this to the triboelectrification process. Higher collection efficiencies due to triboelectrification have also been reported ${ }^{2}$ for a spouted bed fillter.

\section{CONCLUSIONS}

Granular bed filters provide high filtration efficiencies for filtering fine dust or mist in the particle size range around $1 \mu \mathrm{m}$. Compared with more 


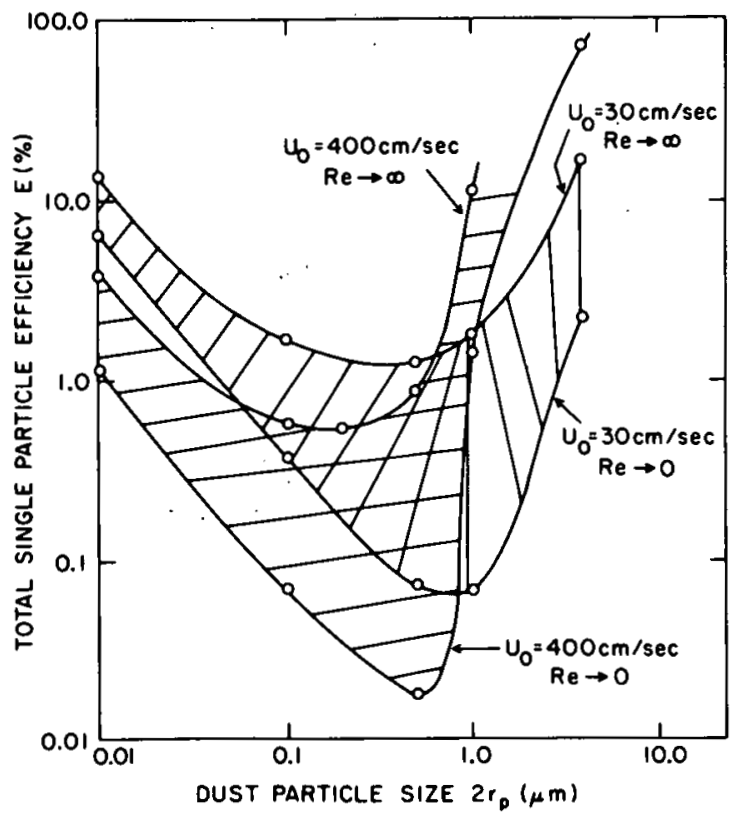

Figure 18. Varlation of total single-particle efficiency with dust particle size.

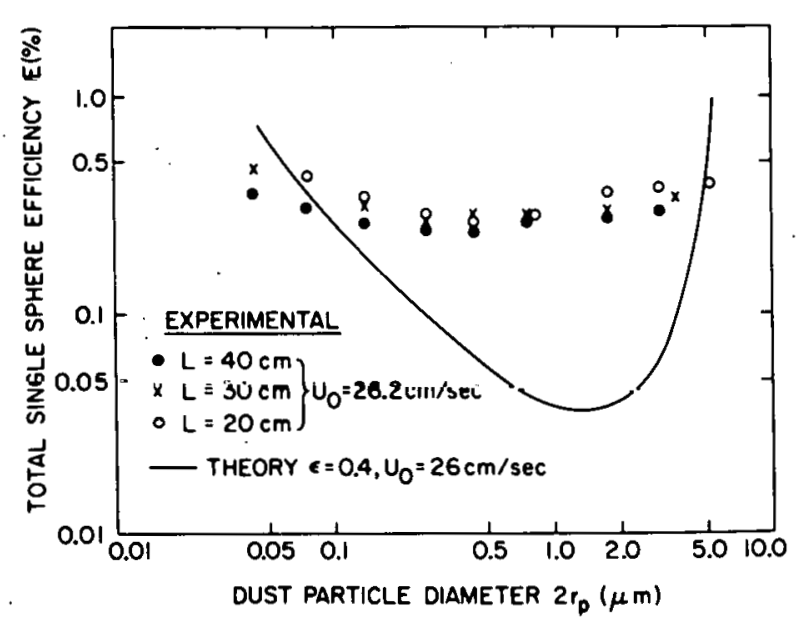

Figure 20. Total single-sphere efficiencies vs. particle diam. Experiment with cement dust $(0.1$ $8 / \mathrm{m}^{3}$ ) flowing through a hed of $2 a=1 \mathrm{~mm}$ plastic spheres (porosity $\varepsilon=0.4$ ).

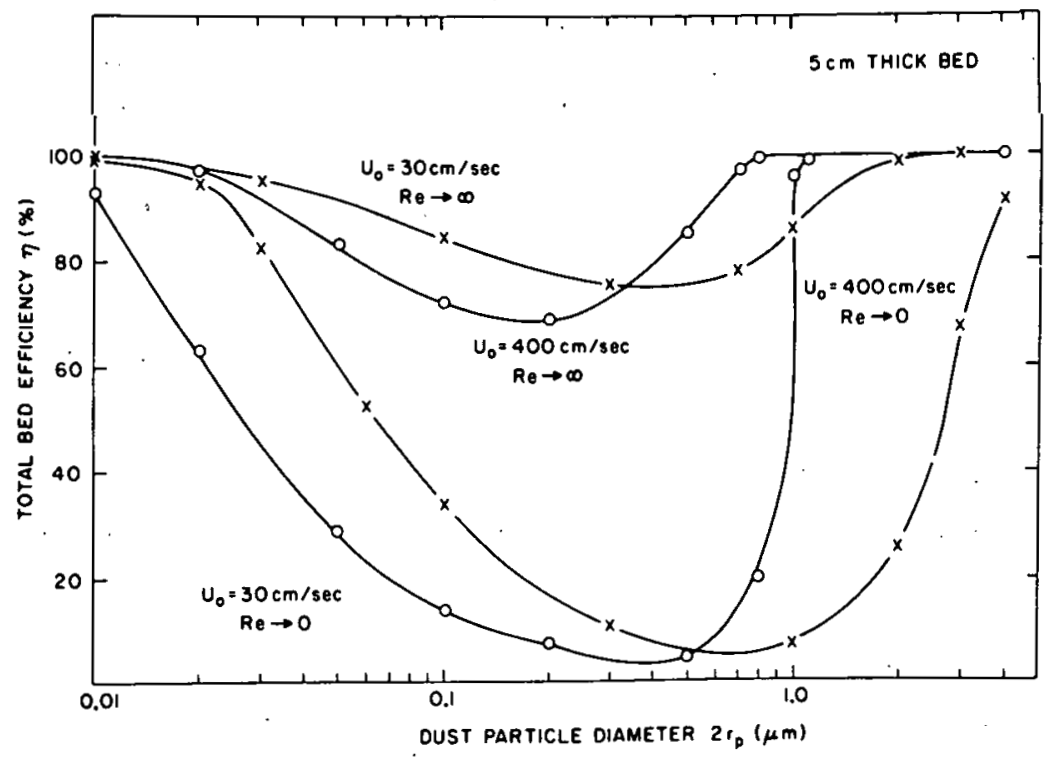

Figure 19. Variation of total granular bed efficiency with dust particle size.

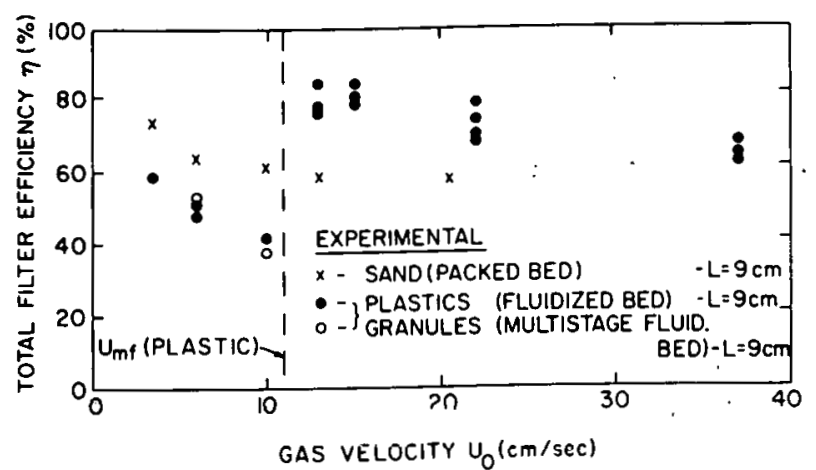

Figure 21. Total filter bed efficiency vs. superficlal gas velocity. Experiment with beds of sand $(\varepsilon=0.4)$ and plast1c granules $(\varepsilon=0.37)$ of $2 a=360 \mu$, filtering latex aerosols: $2 r_{p}=0.481 \mu \mathrm{m}$. 
conventional particulate removal equipment for this dust size range (electrostatic precipitators, bag filters, Venturi scrubbers), they are attractive where process conditions require (1) use of an inert collector capable of withstanding elevated temperatures as in combustion processes, coal gasification, etc., or (2) simultaneous air pollutant absorption and particular filtration, e.g., to remove $\mathrm{H}_{2} \mathrm{~S}$ and alkali fume from a coal gasifier. With fixed beds the need to clean or regenerate the collector granules requires cyclical operation or the use of a moving bed through which the collector granules circulate slowly. Fluidized beds offer the possibility of continuous operation, low pressure drop, and increased collection efficiencies due to the triboelectrification effect but cannot be operated at velocities much higher than minimum fluidization because bubbling beds have lower collection efficiencies due to bypassing of dust particles in the bubble phase. This severely limits the use of fluidized beds as commercial filters because of the excessive bed area that would be required.

The rotating fluidized bed presents a novel means of overcoming this limitation since the minimum fluidization velocity can be increased to many times that of a conventional fluidized bed simply by increasing the rotational speed of the bed. Furthermore, operation of a rotating fluidized bed at a minimum fluidization velocity of $400 \mathrm{~cm} / \mathrm{sec}$, say, compared with 20 to $30 \mathrm{~cm} / \mathrm{sec}$ in a conventional fluidized bed will shift the minimum filtration efficiency of the bed to a smaller sized dust particle and will also take advantage of the higher collection efflciencles obtalned for high than for low Reynolds number flow (see Figure 18). Running at a substantially higher velocity will increase the pressure drop across the bed, but this is true for any type of granular bed filter including packed and moving bed filters.

Since the only experimental data ${ }^{4}$ for rotating fluidized bed filters are inconclusive, it is not known whether the high gas velocities through the bed and the tangential velocities produced by the rotacion of the distributor will tend to cause reentrainment of dust particles already collected by the granules and thus lower the expected overall filtration efficiencies. The answer to this important question can be obtained only by carefully designed experiments. 
One of the problems associated with fluidized bed filters is the possibility of clogging the distributor when filtering gases containing dust of wide size distribution, including large as well as smail particles. For such applications it might be necessary to remove the large particles. in a cyclone or other device before sending the dusty gas to the fluidized bed filter. Since a cyclone is efficient only for filtering dust particles of size $\geq 15 \mu \mathrm{m}$, and the smaller particles leave with the exit gas in the cyclone's outlet tubes, it seems logical to combine the large-particle filtering capability of the cyclone with the small-particle filtering capability of the rotating fluidized bed and thus produce a highly efficient filter for a large spectrum of particle sizes as well as avoid problems of clogging of the distributor in the rotating fluidized bed. One such device designed by Pfeffer and Tardos, (Figure 22) has the rotating fluidized bed simply fitted in the cylindrical exit tube of a conventional cyclone. Dirty granules are continuously removed from the bottom of the rotating fluidized bed together with the large dust particles collected by the cyclone.

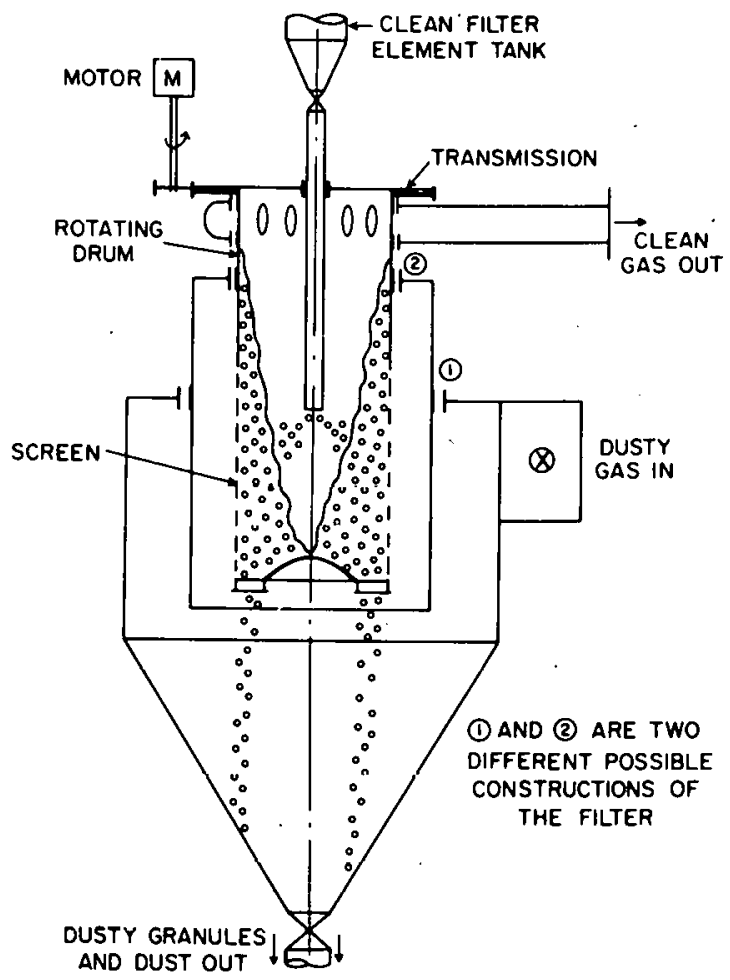

F1gure 22. Combined cyclone separator and rotating fluldized bed filter. 
Clean granules are added to the rotating bed from a hopper at the top. Since the rotating fluidized bed can be run at velocities much higher than those in a conventional fluidized bed, and since the height of the bed can also be varied, it turns out that the entire filter can be operated at the recommended inlet velocity of a standard cyclone. Further design studies and experiments are necessary to determine whether such a device is indeed feasible as a high efficiency dust filter.

\section{NOMENCLATURE (IN CGS UNITS).}

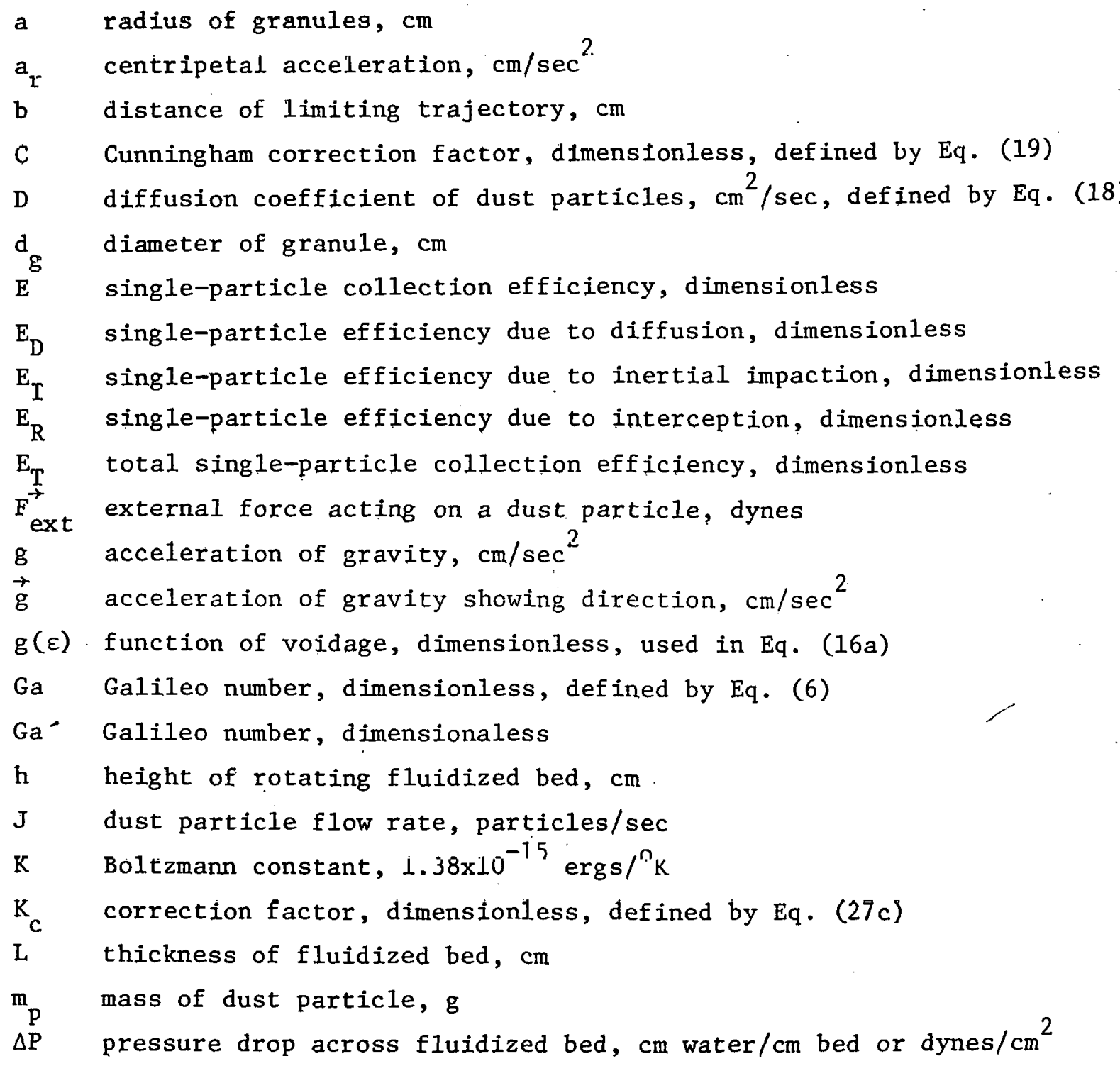


Pe Peclet number, dimensionless, defined by Eq. (17)

$Q \quad$ volumetric flow'rate of $\mathrm{gas}, . \mathrm{cm}^{3} / \mathrm{sec}$

$r$ radial distance from axis of rotation, or radial coordinate in $x, y$ plane, $\mathrm{cm}$

$r_{i}$ inner radius of rotating fluidized bed, $\mathrm{cm}$

$r_{0} \quad$ outer radius of rotating fluidized bed, $\mathrm{cm}$

$r_{p}$

$R_{P}$

$\operatorname{Re}$

$\operatorname{Re}_{\mathrm{mf}}$ radius of dust particle, $\mathrm{cm}$ interception parameter, $\mathrm{r}_{\mathrm{p}} / \mathrm{a}$, dimensionless grain Reynolds. number, dimensionless

Reynolds number at minimum fluidization, dimensionless, defined by Eq. (7)

Sh Sherwood number, dimensionless

St Stokes number, dimensionless, defined by Eq. (22)

$t$ Dimensionless time, as used in Eq. (23)

$\mathrm{T}$ absolute temperature, ${ }^{\circ} \mathrm{K}$

$\mathrm{U}_{\mathrm{mf}}$ velocity at minimum fluidization, $\mathrm{cm} / \mathrm{sec}$

$\mathbf{u}_{0}$ superficial velocity through a bed of particles, $\mathrm{cm} / \mathrm{sec}$

$V_{p} \quad$ terminal settling velocity of a dust particle, $\mathrm{cm} / \mathrm{sec}$

$V_{t} \quad$ tangential velocity, $\mathrm{cm} / \mathrm{sec}$

$V_{\theta} \quad$ velocity of gas in the $\theta$ direction, $\mathrm{cm} / \mathrm{sec}$

$X, Y$ coordinates in the $x, y$ plane, dimensionless, defined by Eqs. (23) and (24)

$\varepsilon \quad$ void fraction, dimensionless

$\varepsilon_{\mathrm{mf}}$. void fraction at minimum fluidization, dimensionless

$\eta \quad$ overall filtration efficiency for a granular bed, dimensionless

$\mu \quad$ viscosity of air, $\mathrm{g} / \mathrm{cm}-\mathrm{sec}$

$\checkmark \quad$ kinematic viscosity of the air, $\mathrm{cm}^{2} / \mathrm{sec}$

$\phi_{s} \quad$ sphericity of granules, dimensionless

$\rho_{\mathrm{f}} \quad$ density of air, $\mathrm{g} / \mathrm{cm}^{3}$

$\rho_{\mathrm{g}}$ density of granules, $\mathrm{g} / \mathrm{cm}^{3}$

$\rho_{\mathrm{p}}$

$\theta$ polar coordinate $i$.n the $x, y$ plane, radians

$\omega_{0}$ rotational speed of distributor, $\mathrm{rad} / \mathrm{sec}$ 
1. Anderson, D. M. and Silverman, L. (1958) Mechanisms in Electrostatic Filtration of Aerosols With Fixed and Fluidized Granules, Harvard U., Boston, MA.

2. Balusubramanian, M., Meisen, A., and Mathur, K. B. (1978) Can. J. Chem. Eng. 56, 298.

3. Black, C. H. and Boube1, R. W. (1969) Ind. Eng. Chem. Process Des. Dev. $8,573$.

4. Boube1, R. W. and Junge, D. C. (1973) ATChE Symp. Ser. No. 128, 69, 138.

5. Chao, B. T. (1969) J. Heat Transfer, Trans. ASME, 91, 273.

6. Chen, C. Y. (1955) Chem. Rev. 55, 595.

7. Chevray, R., Chan, Y. N. I., and Hill, F. B. (1978) Dynamics of bubbles and entrained particles in a rotating fluidized bed. Paper in prcparation.

8. Clift, R. and Thambimuthu, K. V. (1977) Paper in preparation.

9. Davics, C. N. (1973) Nir Filtration, Academic Press, London.

10. Demircan, N., Gibbs, B. M., Swithenbank, J., and Taylor, D. S. (1978) in Fluidization, J. F. Davidson and D. L. Keairns, Editors, Cambridge University Press.

11. Figueroa, A. R. and Licht, W. (1978) AIChE Symp. Ser. No. 175, 74, 17.

12. Friedlander, S. K. (1958) Ind. Eng. Chem. 50, 1161.

13. Geffken, J., Guillory, J. L., and Phillips, K. E. (1978) Performance characteristics of moving bed granular filters. Paper presented at 1st Int. Symp. on Transfer and Utilization of Particulate Control Technology, Denver.

14. Gutfinger, C., Abuaf, N., and Tardos, G. (1975) in Proc.6th Sci. Conf. Israel Ecological Soc., Tel Aviv.

15. Happe1, J. (1958) AIChE J : 4, 197.

16. Herne, H. (1960) Int. J. Air Pollut. 3 , 26.

17. Ishii, T. and Johnson, A. I. (1970) Can. J. Chem. Eng. 48, 56.

18. Kalen, B. and Zenz, F. A. (1974) AIChE Symp. Ser. No. 137, 70, 397.

19. Knetting, P. and Beekmans, J. M. (1974) Can. J. Chem. Eng. $\overline{52}, 703$.

20. Kunii, D. and Levanspiel, 0. (1969) Fluidization Engineering, wiley, New York.

21. Kuwabara, S. (1959) J. Phys. Soc. Japan 14, 527.

22. Lamb, H. (1932) Hydrodynamics, 6th ed., Cambridge University Press.

23. Levich, V. G. (1962) Physiochemical Hydrodynamics, Prentice-Ha11, Englewood Cliffs, NJ.

24. Levy, K. K., Lodge, L., and Chen, J. C. (1976) Paramelril analysis of a centrifugal fluidized bed coal combustor. Paper presented at Nat. Heat Transfer Conf., St. Louis, MO.

25. Leyy, E. K. and Chen, J. C. (1977) Centrifugal fluidization: A review. Paper presented at Int. Powder and Bulk Solids Handling and Processing Cont., Kosemont, IL.

26. Levy, E. K., Martin, N., and Chen, J. (1978) in Fluidization, J. F. Davidson and D. L. Keairns, Editors, Cambridge University Press.

27. Lindauer, G. C., Tichler, P., and Hatch, L. P. (1966) Experimental Studies of High-Gravity Rotating Fluidized Beds, BNL 50013 (T-435).

28. McCarthy, D., Yanke1, A. J., Patterson, R. G., and Jackson, M. L. (1976) Ind. Eng. Chem. Proc. Des. Dev. 15, 266. 
29. Meisen, A. and Mathur, K. B. (1974) The spouted bed aerosol collector: A rovel device for separating small particles from gases, in Multi-Phase Flow Systems Symp., Inst. Chem. Engrs. Symp. Ser. No. 38, paper K3.

30. Meissner, H. P. and Mickley, M. S. (1949) Ind. Eng. Chem. 41, 1238.

31. Metcalfe, C. I. and Howard, J. R. (1977) App1. Energy $\frac{3}{3}, 65$.

32. Michael, D. H. and Norey, P. W. (1969) J. Fluid Mech. 37, 565.

33. Neale, H. N. and Nader, W. K. (1974) AIChE J. 20, 530.

34. Payatakes, A. C., Tien, C., and Turian, R. M. (1974) AIChE J. 20, 889.

35. Paretsky, L., Theodore, L., Pfeffer, R., and Squires, A. M. (1971) J. Air Pollut. Control Assoc. 21, 204.

36. Pféffer, R. (1964) Ind. Eng. Chem. Fundam. 3 , 380 .

37. Pich, J. (1966) Theory of aerosol filtration by fibrous and membrane filters, in Aerosol Science, C. N. Davies, Editor, Academic Press, New York.

38. Prieve, D. and Ruckenstein, E. (1974) AIChE J. 20, 1178.

39. Rajagopalan, R. and Tien, C. (1976) AIChE J. 22, 523 .

40. Scott, D. S. and Guthrie, D. A. (1959) Can. J. Chem. Eng. 37, 200.

41. Tam, C. K. W. (1969) J. Fluid Mech. 38, 537.

42. Tardos, G. I., Gutfinger, C., and Abuaf, N. (1974) Isr. J. Technol. 12, 184.

43. Tardos, G. I., Gutfinger, C., and Abuaf, N. (1976) AIChE J. 22, 1147.

44. Tardos, G. I., Abuaf, N., and Gutfinger, C. (1976) Atmos. Environ. 10, 389.

45. Tardos, G. I. (1977) The Granular Bed Filter, Theory and Experiments, Ph.D. Dissertation, The Technion-Israel Institute of Technology.

46. Tardos, G. I., Abuaf, N., and Gutfinger, C. (1978) J. Air Pollut. Control Assoc. 28, 354 .

47. Thomas, J. W. and Yoder, R. F. (1956) AMA Arch. Ind. Health 13, 545.

48. Yao, K. M., Hahibian, M. T., and O'Melia, C. R. (1971) Environ. Sci. Technol. $\underline{5}, 1105$. 